\title{
Modelos críticos e teoria social tradicional A dialética entre pesquisa e apresentação em Georg Lukács e Max Horkheimer
}

\author{
Mariana Oliveira do Nascimento Teixeira ${ }^{1^{*}}$
}

Resumo: O que faz de uma teoria social uma teoria crítica da sociedade? $\mathrm{O}$ que a distingue de outras maneiras ("tradicionais") de descrever, compreender e avaliar a realidade social? E como se dá a relação entre ambas? Questões como essas aparecem, ao longo do desenvolvimento da chamada teoria crítica, como centrais para a sua própria constituição e para a definição de sua peculiaridade enquanto teoria da sociedade. A despeito da diversidade das respostas dadas a esse campo de problemas pelos diferentes autores dessa corrente teórica, é possível concebêlas de modo unitário na medida em que sejam consideradas como formulações diversas de uma mesma ideia básica acerca das rupturas e continuidades entre pensamento crítico e ciência tradicional: o caráter eminentemente histórico que o primeiro assume de modo consciente em relação a si mesmo, bem como em relação a todo pensamento teórico, conduz a que a segunda seja, no interior do pensamento crítico, ao mesmo tempo afirmada (em sua parcialidade) e negada (em sua pretensão irrefletida de abarcar o todo social). Este trabalho procura apresentar os contornos gerais dessa ideia e sua aplicação prática na obra de dois autores decisivos para a consolidação inicial da teoria crítica, Georg Lukács e Max Horkheimer, com especial atenção ao problema da apropriação das ciências empíricas especializadas. A partir dessa análise e de um breve exame crítico da posição de Jürgen Habermas sobre o assunto, procura-se avaliar os limites e as possibilidades de atualização dos modelos lukácsiano e horkheimeriano na direção de uma teoria crítica que tenha como referência fundamental a dialética, desenvolvida inicialmente por Marx, entre pesquisa e apresentação.

Palavras-chave: Lukács, G. — Horkheimer, M. — Dialética Materialismo Interdisciplinar - Totalidade.

1 * Doutoranda em Filosofia no Instituto de Filosofia e Ciências Humanas da Universidade Estadual de Campinas (UNICAMP). 


\begin{abstract}
What is it that makes a social theory a critical theory of society? What distinguishes it from other ("traditional") attempts to theoretically depict, understand and evaluate social reality? And how do they relate to each other? Such issues appear as central, in the development of critical theory, to the definition of its peculiarity as a theory of society. Despite the diversity of responses presented by different authors in the critical field to these questions, it is possible to conceive them in a unified way to the extent that they are considered as various formulations of the same basic idea concerning the ruptures and continuities between critical thought and traditional science: the historical character the first recognizes in relation to itself, as well as in relation to every form of theoretical thinking, leads to the fact that the second is, within critical thought, at the same time affirmed (in its partiality) and denied (in its unreflected claim to have grasped the social whole). This paper aims to present the general outlines of this idea and its practical application in the work of two authors that are decisive for the early establishment of critical theory, Georg Lukács and Max Horkheimer, with particular regard to the problem of the appropriation of specialized empirical sciences. From this analysis and from a brief critical review of Jürgen Habermas's position on the matter, this article seeks to assess the limits and possibilities of actualizing the lukácsian and horkheimian models towards a critical theory that has the dialectics between research and presentation, initially developed by Marx, as a fundamental reference.
\end{abstract}

Keywords: Lukács, G. - Horkheimer, M. - Dialectics Interdisciplinary Materialism — Totality

\title{
Introduçãa $0^{2}$
}

\section{No prefácio crítico que escreveu em 1967 para História e}

2 A noção de modelos críticos é apenas um dentre os inúmeros insights teóricos presentes neste texto que foram estimulados e informados pelas discussões realizadas no âmbito do Núcleo Direito e Democracia, ligado ao Cebrap. Fica aqui o agradecimento aos membros do grupo, e em especial a Marcos Nobre, não apenas pelos debates propriamente teóricos, mas também por mostrar que é possível, hoje, construir um ambiente coletivo e interdisciplinar de pesquisas com orientação crítica. Agradeço também a Arthur Bueno, pela leitura e discussão do texto, e ao CNPq, pelo financiamento desta pesquisa. 
consciência de classe, o filósofo húngaro Georg Lukács censura a si mesmo pela tentativa, nessa obra de juventude publicada 44 anos antes, de ter sido mais hegeliano do que o próprio Hegel. ${ }^{3}$ Adespeito do tom acusatório, a constatação não deixa de ser justificada: com uma interpretação do marxismo fortemente inspirada no método hegeliano, História e consciência de classe levou até o limite a dialética como forma de conhecimento da realidade, procurando com isso superar, a partir de uma perspectiva centrada na ideia de totalidade, as antinomias entre sujeito e objeto, pensamento e ser, teoria e prática. Algo que, segundo o Lukács de 1967, nem Hegel teria conseguido realizar em sua plenitude.

A introdução da história na filosofia, por sua vez, é saudada entusiasticamente por Lukács como a grande contribuição hegeliana, ao lado do método dialético, para a compreensão do mundo social: ${ }^{4}$ reconhecendo sua própria historicidade - isto é, sua decorrência das figuras passadas do pensamento, sua inserção no momento histórico em que se manifesta e as consequências dos seus distintos modos de aplicação prática -, a filosofia coloca explicitamente para si a tarefa de compreender o momento presente, o mundo que lhe é contemporâneo. Lukács ressalta, contudo, que Hegel acabou por suprimir, na conclusão de seu sistema filosófico, a própria história, recaindo assim em uma "mitologia conceitual"5, segundo a qual, em última instância, a produção da história existe apenas na imaginação especulativa, na

3 LUKÁCS, G. "Prefácio [1967]", in: História e consciência de classe (daqui em diante: HCC), p. 25.

4 Cf. a parte final de "As antinomias do pensamento burguês", segunda seção do ensaio sobre a reificação (LUKÁCS, G. "A reificação e a consciência do proletariado", in: $\mathrm{HCC}$ ).

5 LUKÁCS, G. "Prefácio [1967]”. 
consciência filosófica - sempre alcançada somente post festum. O problema de Hegel estaria, portanto, em não ter sido fiel ao seu próprio método, ou, nos termos de Lukács: em ter compreendido mal a si mesmo, de modo que a efetivação do programa da filosofia da história de Hegel dar-se-ia "à custa do aniquilamento da doutrina hegeliana". ${ }^{6}$ Em decorrência disso, para Lukács, a ruptura de Marx e do marxismo dialético com Hegel consiste em uma radicalização da própria teoria hegeliana. A crítica de Marx a Hegel representaria, assim, a continuação da crítica que o próprio Hegel havia dirigido a Kant e Fichte. ${ }^{7}$ Em um desenvolvimento consequente do próprio pensamento hegeliano, Marx "levou a tendência histórica que se encontra na filosofia hegeliana à sua lógica extrema. Transformou radicalmente todos os fenômenos da sociedade e do homem socializado em problemas históricos, mostrando concretamente o substrato real da evolução histórica e tornando-a fecunda em seu método". ${ }^{8}$

O esforço lukácsiano para se desfazer dos aspectos idealistas da filosofia hegeliana de fato pode não ter se realizado de maneira completa: a categoria da "totalidade" e a busca por um "sujeito-objeto idêntico", para citar duas instâncias centrais, ocupam na sua teoria um papel ainda demasiadamente central, o que carece de plausibilidade no contexto filosófico e teóricosocial contemporâneo. Não é sem razões, porém, que a tradição da teoria crítica tenha tomado História e consciência de classe como seu ponto de partida. De maneira similar ao filósofo húngaro, os pensadores filiados a essa corrente teórica valorizam

6LUKÁCS, G. “O que é marxismo ortodoxo?”, in: HCC, p. 89 e 94, respectivamente. 7 Ibid. p. 91.

8 Ibid. 
sobretudo o caráter eminentemente histórico introduzido por Hegel no domínio filosófico, tornando-o dessa maneira adequado à consciência histórica que caracteriza a própria modernidade. ${ }^{9}$ Como Lukács, eles procuraram livrar a teoria hegeliana do peso metafísico de sua filosofia da história, formulada ainda no contexto do idealismo alemão, embora sem abrir mão de uma noção de totalidade.

À pergunta de como manter a intuição hegeliana central sem os aspectos problemáticos de sua metafísica idealista o filósofo francês Stéphane Haber sugere, como resposta, uma conexão mais sólida e mesmo "constitutiva" com as ciências sociais: "em um contexto pós-metafísico, a filosofia pode assumir sua própria historicidade e afirmar sua vocação para pensar o presente histórico sob a condição de estabelecer laços muito firmes, constitutivos de seu próprio proceder, com os saberes positivos que já tomam esse mesmo presente por objeto e se consagram à sua exploração empírica". E Haber continua: "Ela [a filosofia] deveria então estabelecer uma ligação orgânica com as ciências sociais, na medida em que podemos supor que estas estão doravante em condições de desenvolver um saber metódico e empiricamente fundado do mundo contemporâneo, sem o qual todo discurso sobre o presente histórico arrisca revelar-se vazio e arbitrário". ${ }^{10}$

Essa valorização da importância das ciências sociais de cunho empírico para a filosofia foi conscientemente convertida em programa teórico, nos anos 1930, por Max Horkheimer e os

9 Sobre isso cf. especialmente HABERMAS, J. O discurso filosófico da modernidade, caps. 1 e 2, mas também, por exemplo, HORKHEIMER, M. "The Present Situation of Social Philosophy and the Tasks of an Institute for Social Research", p. 2.

10 Haber, Habermas et la sociologie, p. 7-8 (tradução M. T.). 
demais pensadores ligados ao Instituto de Pesquisa Social de Frankfurt (Institut für Sozialforschung), assim como por diversos outros teóricos sociais críticos posteriores. A autorreflexividade da filosofia, especialmente quanto ao seu caráter histórico-social, levou desde então os representantes da teoria crítica a elaborarem seus modelos explicativos e normativos a partir da identificação de déficits teóricos nos modelos críticos anteriores, mas também em uma conexão orgânica com um diagnóstico da época envolvendo a detecção das crises e patologias sociais típicas da época moderna, bem como a descrição mais pormenorizada do seu estado atual - o que somente pode ser levado a cabo com a ajuda de investigações no campo das ciências sociais. ${ }^{11}$ O desenvolvimento da teoria crítica é assim marcado pela tensão entre, de um lado, o constante intento de afirmar a sua peculiaridade em relação aos paradigmas teóricos tradicionais e, de outro, o produtivo diálogo e até a cooperação que ela estabelece com esses paradigmas. Independentemente de como se nomeiam esses dois polos ("economia política" versus "crítica da economia política", "ciência burguesa" versus "perspectiva do proletariado", "teoria tradicional" versus "teoria crítica" etc.), um ponto em comum entre os teóricos críticos está em que todos eles procuraram, a esse respeito, partir sempre do que consideravam o estágio mais avançado dos conhecimentos sociais disponíveis para formular o seu próprio modelo teórico. ${ }^{12}$ Cada um incorporou

11 Procuraremos mostrar que a formulação do diagnóstico, entretanto, não é posterior à elaboração do modelo crítico, mas a rigor também não lhe é anterior: trata-se de uma relação de efeitos recíprocos, em que elementos descritivos e normativos imiscuem-se sem permitir uma separação mais rígida - tanto no sentido lógico quanto no cronológico.

12 Cf. Horkheimer, "Teoria tradicional e teoria crítica" (daqui em diante: TTTC), p. 156. 
significativamente, à sua maneira, ideias ou intuições presentes nos quadros conceituais que, de resto, buscaram criticar. Sem abrir mão de sua especificidade, a teoria crítica se recusa, não obstante, a descartar sem mais todo o conjunto da produção teórica "tradicional". 13

Contudo, a incorporação dessa produção teórica não se dá, como veremos, de maneira arbitrária; ela obedece a determinados padrões definidos pelos autores-embora nem sempre explicitamente - e em estreita relação justamente com o que consideram ser a peculiaridade da teoria crítica. Desenvolvemos neste artigo o posicionamento acerca dessa relação em dois autores-chave que representam os marcos iniciais decisivos no trajeto da teoria crítica no século XX: Georg Lukács e Max Horkheimer. Trata-se de discutir, então, o que é considerado por cada autor como a peculiaridade de uma teoria crítica da sociedade - levando em consideração, para tanto, como o diagnóstico de tempo dos diferentes períodos leva os autores a criticar os déficits dos modelos críticos anteriores. Esse pano de fundo permite que se compreenda o tipo de laço que cada um estabelece com ramos das ciências sociais nem sempre pertencentes ao paradigma crítico.

A primeira etapa consiste na análise da interpretação lukácsiana, em História e Consciência de Classe, do legado crítico de Marx - interpretação que, mesmo sem ser ainda

13 Os conceitos de "teoria crítica" e "teoria tradicional", como se pode observar no texto seminal de Horkheimer, são relacionais, isto é: cada um depende do outro para ser definido. Assim, não é necessário fornecer uma "definição" para a teoria tradicional. Ela é tomada, aqui, em sentido lato, como toda produção teórica que claramente diverge da caracterização básica da teoria crítica, especialmente aqueles trabalhos com forte teor empírico ou descritivo que renunciam a um ponto de vista orientado para a emancipação. 
designada pelo termo "teoria crítica", foi fundamental para os seus desenvolvimentos posteriores. A segunda referência crucial nesse caminho é a elaboração do projeto teórico do Instituto nos anos 1930, realizada por Horkheimer num diálogo tácito com as ideias de Lukács.

Ao cabo desse trajeto, estarão dadas as condições para que seja verificada nossa hipótese central: a de que a apropriação de teorias sociais de extração tradicional não é um aspecto secundário do campo crítico, mas sim um fio condutor que orienta os escritos dos teóricos analisados neste artigo, e que poderia ser expandido, acreditamos, para os demais representantes da tradição crítica. Essa conexão - que por vezes se manifesta como apropriação dialética, por outras como colaboração entre polos complementares - é fundamental para que possam ser elaborados novos modelos críticos na medida em que ela assume um papel decisivo na formulação de um diagnóstico de tempo e, assim, na superação dos déficits teóricos dos modelos precedentes.

Procura-se, por fim, apontar também as limitações dos modelos críticos abordados e sugerir caminhos para o desenvolvimento de suas potencialidades. Para tanto, faz-se necessário referir-se brevemente à obra de Jürgen Habermas e mostrar como, hoje, seria possível atualizar as intenções críticas de Lukács e projeto interdisciplinar de Horkheimer sem desconsiderar os desdobramentos mais recentes da teoria crítica.

\section{Georg Lukács e o método dialético.}

Diagnóstico do tempo: em busca do sujeito revolucionário

Entre o fim da década de 1910 e início da década de 1920, momento em que escreve os principais ensaios que compõem História e consciência de classe, Georg Lukács encontra-se sob forte 
impacto não apenas da Revolução Russa, mas também da intensa agitação política que marcou a Europa pós-I Guerra Mundial. Seu próprio país natal tornou-se uma república comunista em 1919, tendo Lukács assumido o cargo de Ministro da Cultura durante os poucos meses de vida da República Soviética Húngara, antes de refugiar-se em Viena e, em seguida, transferir-se para Moscou. ${ }^{14}$

Não é de espantar, portanto, que o livro considerado fundador do "marxismo ocidental" seja permeado por uma aguda consciência do caráter decisivo do momento presente, acompanhada de uma vigorosa confiança na iminência de levantes operários revolucionários. Estariam dadas - como Lukács afirma em mais de um trecho de seu livro - as condições objetivas e subjetivas para a revolução; é preciso, no entanto, que o proletariado assuma livremente a missão histórica a que está destinado: conduzir a humanidade a uma sociedade sem classes.

Se é evidente, por um lado, que Lukács toma as análises econômicas de Marx como ponto de partida (como afirma o próprio autor logo no início do ensaio sobre a reificação), cabe acrescentar, por outro, que sua meta é justamente desenvolver o que ele considera ter faltado na teoria marxista: uma análise das relações recíprocas entre a posição da classes sociais no processo de produção e reprodução do capital e a consciência que cada uma delas tem - ou pode vir a ter - a respeito de sua situação na luta de classes. ${ }^{15}$ Sem uma teoria da consciência, faltariam os meios

14 Cf. CONGDOM, L. The Young Lukács.

15 Diz Lukács: "De uma maneira funesta, para a teoria e o proletariado, a principal obra de Marx interrompe-se justamente no momento em que aborda a definição de classes. [...] O que significa então a consciência de classe?" ("Consciência de classe", in: HCC, p. 133). Sobre a relação entre o jovem Marx e o jovem Lukács, cf. FEENBERG, A., Lukács, Marx and Sources of Critical Theory. 
para se inquirir acerca do sujeito revolucionário, das condições subjetivas da revolução - e é precisamente isso, para Lukács, o que aquele momento histórico exigia de uma intervenção teórica que se pretendesse emancipatória.

À primeira vista, contudo, salta aos olhos que a maior parte dos pensadores a cuja obra Lukács recorre para caracterizar a tendência à reificação da consciência sob o capitalismo moderno seja composta, para além do onipresente recurso às análises de Marx e Engels, por sociólogos e filósofos de fora do campo do marxismo - e muitas vezes até com posições opostas a ele, sobretudo em termos metodológicos. A referência a outros autores marxistas, por sua vez, é muito mais escassa (descontando-se as diversas referências críticas de Lukács às correntes "vulgares" do marxismo, temos apenas Rosa Luxemburgo e Lênin como nomes de destaque ${ }^{16}$ ). A teoria social feita por autores "burgueses" demonstra ter, portanto, um lugar legítimo na construção lukácsiana de uma teoria dialética e com intenção emancipatória.

A contraposição entre o que Lukács chama de "ciência burguesa" e "ponto de vista do proletariado" pode ser considerada o protótipo daquela entre teoria crítica e teoria tradicional, desenvolvida posteriormente por Horkheimer. Para entender o que isso significa, é contudo necessário que retomemos muito brevemente o argumento central de História e Consciência de Classe, uma vez que é com base na teoria aí desenvolvida acerca da distinção fundamental não só entre a posição social das classes capitalista e trabalhadora, mas também entre a forma de conhecimento que provém de cada uma, que Lukács

16 Sobre o papel desses dois grandes nomes do marxismo no pensamento de Lukács, cf. nota 37, adiante. 
afirma a peculiaridade do método dialético e a possibilidade da incorporação da teoria social "burguesa".

"Ciência burguesa" e "ponto de vista do proletariado"

Em "A reificação e a consciência do proletariado", principal ensaio do livro, Lukács pretende mostrar como a sociedade capitalista moderna, baseada na forma-mercadoria, é composta por sujeitos cuja consciência se encontra cada vez mais profundamente reificada: eles obedecem a "leis" sociais que lhes aparecem como uma segunda natureza e que, desse modo, dominam de forma exterior as ações dos sujeitos na sociedade. Esse fenômeno diz respeito tanto à classe trabalhadora quanto à burguesia: a consciência reificada é a forma que domina o conjunto da sociedade capitalista. Sob o domínio dessas "leis", portanto, os atores sociais se limitariam a uma atitude contemplativa frente à realidade social: eles não fariam mais do que calcular, com recurso a uma racionalidade meramente instrumental, os melhores meios para alcançar fins estabelecidos prévia e exteriormente a eles próprios. No quadro da reificação, fica excluída a atitude prática em sentido autêntico - aquela em que o sujeito da ação age como tal, como sujeito dos processos históricos, e não como um "objeto" que obedece a leis sociais intransponíveis, assumidas como naturais.

Uma vez que a meta de Lukács envolve não apenas compreender melhor o funcionamento do capitalismo, mas também desvelar o sujeito que seria capaz de superá-lo, seu argumento central é o de que, apesar da realidade reificada ser imediatamente a mesma para todas as classes sociais, o conhecimento que cada uma pode ter dessa realidade difere radicalmente: enquanto a classe burguesa (aí incluída a pequena burguesia) permanece presa à superfície da realidade imediatamente dada, o proletariado 
seria impelido para além dela.

O contraste entre a perspectiva burguesa e a do proletariado é fundado por Lukács na posição que cada classe ocupa no processo de produção do capital. O proletariado, de um lado, caracterizase por vender a sua força de trabalho como uma mercadoria, produzindo outras mercadorias que, apesar de serem frutos do seu trabalho, não pertencem a ele. $\mathrm{O}$ seu próprio trabalho não mais lhe pertence; uma parte dele mesmo, portanto, não mais lhe pertence; e assim ele é dilacerado no seu ser mais profundo. ${ }^{17}$ É essa dilaceração, não obstante, justamente o que impulsiona o proletariado para a superação dessa realidade reificada: para o homem que vende a si mesmo como uma mercadoria, ir além dessa situação é uma questão de vida ou morte. ${ }^{18}$

A situação social da classe burguesa é inteiramente diversa. Lukács afirma que, a partir da posição que ocupa, essa classe se depara na sua realidade imediata com o "dado" de que ela é o sujeito da produção capitalista e, assim, da reprodução social de modo geral. Para o "pensamento burguês", é ele próprio quem controla os processos da vida social e quem tomas as decisões fundamentais. Em contraste com a posição social do proletariado que se vê vendido como uma mercadoria, a situação social do "burguês" é bastante confortável. Não há nela, portanto, nada

17 A afinidade com o tema marxista da alienação é impressionante, e tanto mais surpreendente tendo em vista que os Manuscritos econômico-filosóficos de 1844 foram descobertos apenas em 1932, isto é, nove anos após a publicação de História e consciência de classe.

18 LUKÁCS, HCC, p. 334. Embora haja, no caso do proletariado, esse impulso para superar a reificação, Lukács sublinha inúmeras vezes que tal superação é dada somente de maneira potencial: é preciso que essa tendência seja levada a cabo, de fato, pela ação prática do proletariado. 
que aponte para além de si mesma, que incite e estimule a classe burguesa a procurar as mediações dessa realidade, bem como as tendências de sua superação. A burguesia permanece na imediatidade dada da realidade social, o que a impede de se reconhecer como igualmente dominada pela reificação.

Sendo assim, o proletariado está de início submetido, junto à classe burguesa, à reificação de todas as manifestações da vida; no entanto, o primeiro se sente impotente e aniquilado em sua existência humana, enquanto a última reconhece nessa situação, ao contrário, o seu poder e a sua humanidade.

Uma vez que o conhecimento está indissoluvelmente ligado a esse ser social de cada classe, para Lukács, a "ciência" produzida a partir do ponto de vista do pensamento burguês permanece, também, presa à imediatidade da realidade social, não sendo assim capaz de desvelar as mediações que conformam e estruturam essa realidade para além de sua superfície mais visível. Às teorias burguesas falta, segundo essa interpretação, a dimensão de transcendência do real, que só surge e se torna operante no ser social internamente dilacerado e impelido em direção à totalidade: para Lukács, o proletariado. $\mathrm{O}$ ponto de vista da burguesia é, então, o ponto de vista do indivíduo isolado, perante o qual a sociedade capitalista aparece como um conjunto irracional de leis arbitrárias, o que se expressa também na fragmentação e especialização crescente das ciências (inclusive as ciências sociais); o ponto de vista do proletariado corresponde, em contraste, à perspectiva da totalidade, de onde é possível vislumbrar as relações sociais na sua unidade significativa.

A conclusão que se segue dessa argumentação é a de que o conhecimento produzido a partir do ponto de vista do pensamento burguês nunca poderia alcançar uma descrição profunda e "correta" da realidade, e que o conhecimento partindo do ponto 
de vista do proletariado é o único que pode - na medida em que leve a cabo as tendências presentes na realidade - conduzir não só a uma efetiva compreensão do real, mas, e ao mesmo tempo, à sua radical transformação.

Poder-se-ia fazer decorrer dessa argumentação a necessidade, então, de ignorar toda a produção teórica erigida a partir da perspectiva do pensamento burguês e de voltar a atenção apenas ao que for formulado a partir do ponto de vista do proletariado. Ora, como se explicaria, então, a referência que Lukács faz diversas vezes às teorias de pensadores abertamente "burgueses" (ou distantes do que Lukács considera a "perspectiva do proletariado"), como Max Weber, Georg Simmel e Ferdinand Tönnies, entre outros? É evidente que Lukács não considera que o pensamento destes e de outros teóricos da sociedade deva ser descartado sem mais, como algo puramente ilusório. Como deve ser caracterizada, então, a relação entre o pensamento burguês e o ponto de vista do proletariado? Como a própria teoria lukácsiana se articula com uma forma de pensamento que está "imersa na reificação"?

Ofalso-como falso e como não falso-é um momento do verdadeiro No prefácio de seu livro, Lukács faz algumas considerações que contribuem para o esclarecimento dessa questão: na linha do pensamento dialético iniciada por Hegel, o filósofo húngaro julga ser importante partir do que é inicialmente dado, vale dizer: dos conceitos "unilaterais, abstratos e falsos" 19 elaborados pelos pensadores representantes dos métodos não dialéticos, "burgueses". Ao serem postos em operação no contexto de uma

19 “Prefácio (1922)”, in: HCC, p. 59-60. 
obra dialética, tais conceitos ganham um novo significado, sendo então integrados como momentos numa totalidade que os supera em sua parcialidade.

Podemos então compreender por que Lukács não descarta de saída toda e qualquer elaboração teórica feita por autores que ele reconhece serem representantes do "pensamento burguês": quando confrontado com o ponto de vista da burguesia, o pensamento do proletariado não tem necessidade de anular totalmente o primeiro e partir novamente do início; o ponto de partida do proletariado não é um "recomeço sem pressupostos", mas sim a própria existência da sociedade burguesa e do pensamento burguês. ${ }^{20}$ Desse modo, Lukács estabelece relações com essas teorias parciais a partir dos seus avanços: mas é necessário inseri-los no quadro da totalidade social e conectá-los com o seu fundamento material (o "solo da sociedade burguesa") e, assim, conferir-lhes um sentido específico, de modo que "o 'falso', o 'unilateral' da compreensão burguesa da história aparece como fator necessário para a construção metodológica do conhecimento social". ${ }^{21}$

É nesse sentido que pode ser compreendida a afirmação de Lukács de que “o 'falso' é, ao mesmo tempo, enquanto 'falso' e enquanto 'não falso', um momento do 'verdadeiro"'. ${ }^{22} \mathrm{O}$ falso, o pensamento reificado preso ao solo da sociedade burguesa, é um momento do verdadeiro em dois sentidos: enquanto "falso", isto é, um momento parcial que deve ser superado, mas que é justamente por isso um momento no caminho para o verdadeiro, e enquanto "não falso": um fenômeno que é produto de uma

20 LUKÁCS, HCC, p. 332.

21 LUKÁCS, HCC, p. 333 (tradução modificada).

22 LUKÁCS, "Prefácio (1922)”, p. 60. 
determinada sociedade em um determinado momento e, portanto, revela algo de verdadeiro sobre ela.

Para Lukács, portanto, superar a parcialidade de uma teoria significa considerá-la como um momento da totalidade e, assim, conferir a ela um novo significado nesse contexto do movimento total. Esse posicionamento pode ser comprovado, por exemplo, no uso que é feito em História e consciência de classe de determinadas ideias dos autores citados anteriormente, ${ }^{23}$ especialmente Weber e Simmel - dos quais, aliás, ele foi aluno no início de sua formação intelectual nas primeiras décadas do século passado.

Dois casos concretos: a apropriação de temas weberianos $e$ simmelianos

A importância da apropriação de aspectos da teoria de Weber é evidente sobretudo no papel decisivo que o conceito de "racionalidade" em sua acepção weberiana assume na elaboração da categoria central de História e consciência de classe, sendo articulado internamente à crítica - de extração marxista - do processo de reificação que incide sobre a consciência dos sujeitos que vivem sob o capitalismo moderno. ${ }^{24}$ Os aspectos reificadores que Lukács encontra na caracterização weberiana do progressivo incremento da "racionalidade ocidental" podem ser sintetizados em três eixos estreitamente conectados: (1) a racionalização

23 Lukács considera somente as contribuições dos "representantes realmente originais do pensamento burguês", devendo ser excluídos os "Epígonos, ecléticos e meros defensores dos interesses da classe declinante", que têm sua "verdade" apenas como ilustrações do pensamento puramente reificado (LUKÁCS, HCC, p. 333, nota 127).

24 Para uma análise pormenorizada dessa apropriação e de seu significado para a teoria crítica de Lukács, cf. minha dissertação de mestrado cujos resultados são retomados aqui de maneira sucinta: TEIXEIRA, Razão e Reificação. Um estudo sobre Max Weber em História e Consciência de Classe, de Georg Lukács. 
como aumento da calculabilidade, (2) como preponderância da racionalidade com respeito a fins (ou instrumental) sobre a racionalidade com respeito a valores e (3) como aprofundamento do caráter formal do pensamento. $\mathrm{Na}$ realidade, esses três aspectos estão de tal modo entrelaçados que é difícil pensá-los separadamente: a abstração do conteúdo concreto do existente e a sua formalização em termos gerais é o que permite a sua calculabilidade sob qualquer circunstância - o que, por sua vez, possibilita o cômputo correto dos meios mais adequados para se atingir um determinado fim. A importância dessa concepção de racionalidade é, ainda, atestada pelo fato de que é justamente o seu caráter formal que limita (internamente) a possibilidade de ela dominar por completo a consciência dos atores sociais e, assim, o mundo social como um todo.

As ideias de Weber são a tal ponto inspiradoras para Lukács que ele o chama de um "historiador realmente perspicaz [klarblickend] do capitalismo moderno". De modo significativo, porém, Lukács acrescenta: "Para a consideração do seu material factual, é inteiramente indiferente se concordamos ou não com sua interpretação causal". ${ }^{25}$ Fica claro aqui, portanto, que para Lukács a descrição de fenômenos sociais feita por Weber pode ser de grande serventia para a elaboração de uma teoria dialética (ou "crítica"), mesmo que haja dissonâncias importantes quanto a determinados aspectos da teoria weberiana, especialmente quanto ao tipo de explicação implicado em sua metodologia.

De forma semelhante, as obras de Simmel fornecem uma interpretação crítica da modernidade que será bastante frutífera

25 LUKÁCS, HCC, p. 214 e p. 382, nota 160, respectivamente. 
para Lukács: ${ }^{26}$ como consequência do crescente distanciamento entre as dimensões objetiva e subjetiva da cultura, e o predomínio da primeira sobre a segunda, Simmel fala em uma objetificação do sujeito e da vida. Na esteira de um processo do qual o dinheiro e a economia monetária altamente desenvolvida constituem os símbolos mais visíveis, o mundo passa a poder ser tomado como um conjunto de valores mensuráveis, redutíveis a uma mesma escala quantitativamente determinada; as coisas em geral e os valores pessoais, mesmo aqueles tidos como não quantificáveis, podem então aparecer como meros quanta de valor, estabelecendo as bases para relações cada vez mais objetivas e impessoais entre as pessoas e as coisas; a dimensão qualitativa cede cada vez mais espaço para o meramente quantitativo e a contabilização numérica das coisas, redundando num crescente nivelamento de, potencialmente, todos os valores a uma mesma medida: o dinheiro. Também no que se refere ao motor desse fenômeno, a visão exposta no texto de Lukács se assemelha à interpretação simmeliana: para ambos, a moderna divisão do trabalho, necessária para a produção de mercadorias em massa, impede que os sujeitos produtores identifiquem-se com os objetos que são a expressão da

26 Já nos seus escritos pré-marxistas é possível perceber a marcada influência de Simmel: a ideia de forma, por exemplo - central tanto nos argumentos de Filosofia do dinheiro quanto na sociologia simmeliana e, finalmente, em sua metafísica da vida -, tem um lugar importante em textos metodológicos e estéticos de Lukács. Encontramos, além disso, em seu livro sobre a evolução do drama moderno, a crítica - em voga na época, é verdade, mas detidamente desenvolvida por Simmel no período que Lukács com ele conviveu - ao individualismo, à vida na metrópole, à racionalização e à uniformização crescentes da vida, à dissolução das comunidades, ao isolamento dos seres humanos e à objetificação da vida (cf. FRISBY, "Introduction to the translation", in: SIMMEL, The Philosophy of Money, p. 17-18, 43). 
sua criatividade. ${ }^{27}$ Por todos esses motivos, Lukács afirma que o livro de Simmel é "um trabalho muito perspicaz [scharfsinnig] e interessante em seus detalhes". ${ }^{28}$

Apesar de reconhecer a precisão e a clareza com que Simmel descreve, na Filosofia do dinheiro e em outros textos relacionados, ${ }^{29}$ importantes manifestações do fenômeno da reificação, Lukács faz a ressalva de que o sociólogo alemão acaba, por conta de seu "ponto de vista burguês", obscurecendo a especificidade da origem desse fenômeno - as relações capitalistas que regem sociedade moderna em sua totalidade. ${ }^{30}$

Desse modo, tanto Simmel como Weber, na visão de Lukács, conseguem descrever diversas manifestações da reificação com precisão e riqueza de detalhes, desenvolvendo intuições que se revelaram vitais para apreender esse fenômeno; o que seus textos oferecem é, nos termos da teoria crítica que viria a se desenvolver posteriormente, uma boa fonte para um diagnóstico do tempo presente, sem o qual é impossível elaborar uma crítica imanente da realidade social. ${ }^{31}$

27 Não é à toa que Lukács reconhece a importância de Simmel para a sua aproximação em relação ao marxismo: de forma similar a Marx, porém com diferenças importantes, Simmel aponta a conexão entre a divisão do trabalho, a transformação do trabalho em mercadoria e o fenômeno da alienação - tema do último capítulo de Filosofia do dinheiro.

28 LUKÁCS, HCC, p. 213.

29 Cf. os ensaios reunidos na coletânea O conflito da cultura moderna e outros escritos, que vão de 1908 a 1917.

30 LUKÁCS, HCC, p. 321.

31 É crucial notar aqui que as teorias sociais apropriadas por Lukács - o exame webriano da racionaidade ocidental e a crítica simmeliana às relações monetárias - encontram-se ainda em um nível inicial de especialização, tanto que Weber e Simmel são contados entre os fundadores da sociologia como disciplina acadêmica 
A ausência de um bom diagnóstico de tempo - como aquele fornecido pelas análises weberianas e simmelianas - torna a crítica puramente normativa e, assim, utópica (no sentido negativo presente, por exemplo, na crítica marxiana aos socialistas utópicos). Por outro lado, ainda segundo a perspectiva lukácsiana, entretanto, ao se deterem apenas na formulação do diagnóstico, Weber e Simmel limitam sua visão ao que está dado imediatamente e renunciam, por isso, a ir além da descrição dos fenômenos dados. Utopismo desencarnado (sem imanência) e empirismo realista (sem transcendência) são, na verdade, duas faces da mesma moeda. Assim, para Lukács, apesar de apresentarem boas caracterizações do funcionamento da reificação, tais pensadores não conseguem atingir o "fenômeno originário da reificação", ${ }^{32} \mathrm{o}$ seu fundamento último, aquilo que permite não só compreender sua origem, mas também apontar os possíveis caminhos ou tendências da sua superação. Essa perspectiva só adentra o horizonte teórico a partir do ponto de vista crítico: do contrário, o que é concebido para ser uma mera descrição acaba por se transformar num destino.

Em resumo: para Lukács, é o método dialético da tradição hegelo-marxiana que, ao expressar teoricamente o conhecimento potencialmente inscrito na situação social do proletariado - um conhecimento que remete os momentos parciais da realidade social ao movimento da totalidade -, funda a possibilidade de um ponto de vista crítico e constitui, portanto, a peculiaridade de uma teoria crítica da sociedade;

autônoma. Lukács certamente resistiria a apoiar condução de pesquisas sociais empíricas que utilizam métodos tradicionais, não-críticos, de investigação (como observou-se no Instituto de Pesquisa Social sob a direção de Horkheimer).

32 LUKÁCS, HCC, p. 213. 
também é esse modo de proceder aquilo que, ao mesmo tempo, justifica e estabelece os critérios específicos para a apropriação de teorias sociais produzidas fora dos limites teóricos dialéticos. E são essas teorias sociais sem intenção normativa que, por sua vez, impulsionam as reformulações dos modelos críticos anteriores: trata-se, no caso, da tentativa de complementar a teoria marxista do capitalismo com uma análise crítica dos limites e das possibilidades da ideia de uma consciência de classe, contando para isso com a ajuda das análises sociológicas de pensadores como Weber e Simmel. Cria-se, assim, um jogo entre imanência e transcendência no qual um determinado diagnóstico de patologias sociais é articulado, desde o início, com a possibilidade de sua superação.

Ao analisar as fontes sociológicas de extração tradicional apropriadas por Lukács, salta aos olhos a sua relutância em considerar pesquisas de cunho mais empírico, dando preferência aos aspectos mais filosóficos e gerais dos autores mobilizados. Em seu livro sobre o conceito de "totalidade" nas diferentes correntes do pensamento marxista, Martin Jay destaca que os marxistas ocidentais mais "messiânicos" - que seria o caso de Ernst Bloch e Lukács - tomam a totalidade basicamente como uma categoria não empírica: tentar apreender o todo como um agregado empírico seria buscar aquilo que Hegel condenou como uma "má infinitude". ${ }^{33} \mathrm{O}$ ensaio lukácsiano sobre a "Consciência de

33 JAY, Marxism and Totality, p. 202. O autor chega a falar na totalidade como uma categoria "anti-empírica". 
classe", com a distinção entre uma "consciência psicológica" (ou, sintomaticamente, "empírica"), de um lado, e uma "consciência atribuída", de outro (cf. nota 31, adiante), fornece um belo exemplo desse posicionamento teórico. Assim rebate Lukács as observações com relação à consciência de classe empírica do proletariado, que, por sua suposta passividade, parecia exigir uma revisão da teoria marxista.

Esse é um ponto que distancia Max Horkheimer do filósofo húngaro que tanto influenciou a teoria crítica do Instituto de Pesquisa Social. Enquanto Lukács evita a todo custo falar em fatos (a palavra se encontra sempre entre aspas em História e consciência de classe), o primeiro insiste em levar "fatos desagradáveis" em consideração $0^{34}$ - sem contudo abandonar a pretensão de abarcar a totalidade. Nas palavras de Olivier Voirol: "De um lado, ele [Horkheimer] tenta salvar o projeto científico sem abrir mão da pesquisa empírica, a despeito de sua forte crítica do positivismo. De outro, ele salva a filosofia ao defender a posição particular desta em relação à ciência - sobretudo porque a filosofia admite a perspectiva da totalidade". ${ }^{35}$

Horkheimer parte da constatação de que os modelos de consciência de classe desenvolvidos filosoficamente por pensadores marxistas como Lukács e Karl Korsch não davam conta de explicar a "passividade" da classe trabalhadora, de modo que a dimensão psicológica da reificação tinha que ser aprofundada - algo que tanto Lukács quanto Korsch deixaram de lado. Para Horkheimer, a crítica da ideologia como falsa consciência teria

34 Ibid.

35 VOIROL, O. "Teoria crítica e pesquisa social: da dialética à reconstrução", p. 86. Cf. também JAY, M. Marxism and Totality, p. 202. 
que ser complementada com uma análise psicológica dos motivos, por parte dos dominados, para a aceitação das justificações ideológicas de sua própria dominação. ${ }^{36}$

Como dito inicialmente, a ideia central que orienta a presente investigação consiste em que cada formulação da teoria crítica se desdobra e se desenvolve mediante a tentativa de aprimorar os modelos críticos que lhe antecederam, tendo em vista não apenas questões estritamente teóricas, mas também e principalmente a atualização do diagnóstico de época e as consequências que isso traz para a crítica das patologias sociais. Nem sempre, contudo, esse diálogo é explícito: Horkheimer, por exemplo, não menciona Lukács ou História e consciência de classe uma única vez em "Teoria tradicional e teoria crítica". Escrito e publicado em 1937 na revista do Instituto de Pesquisa Social (a Zeitschrift für Sozialforschung), o ensaio é um marco decisivo na consolidação da ideia da teoria crítica como corrente intelectual relevante na compreensão do presente, no qual percorre subterraneamente um nítido debate com as ideias desenvolvidas por Lukács em "A reificação e a consciência do proletariado".

Se, nesse sentido, Horkheimer contrapõe-se a algumas das ideias basilares do ensaio lukácsiano, é significativo, por outro lado, que ele aceite muitos dos termos do debate aí estabelecidos.

36 Cf. HORKHEIMER, M. "History and Psychology". 


\section{Max Horkheimer e o materialismo interdisciplinar}

Não há consenso entre os estudiosos da teoria crítica do período sobre a medida em que se dão as rupturas e continuidades entre o modelo crítico proposto por Lukács e aquele desenvolvido por Horkheimer no contexto do Instituto de Pesquisa Social na década de $1930 .{ }^{37}$ É possível afirmar, contudo, que as rupturas que marcam essa transição se dão dentro de determinados limites, de forma que um certo núcleo de intuições fundamentais e mesmo uma certa linguagem permanecem em operação nesse novo contexto.

37 Sobre a formação do pensamento de Horkheimer desde a juventude até a década de 1940 e a publicação (em conjunto com Adorno) da Dialética do esclarecimento, cf. o recente e minucioso livro de ABROMEIT, J. Max Horkheimer and the Foundations of the Frankfurt School. Apesar de oferecer uma leitura diferente da apresentada aqui no que tange à importância da teoria lukácsiana para a formação intelectual de Horkheimer, o livro sustenta a tese, com a qual concordamos, de que o primeiro modelo crítico do autor (isto é, aquele que se desenvolve ao longo das décadas de 1920 e 1930) contém uma ênfase na integração entre filosofia e pesquisa social empírica que, ainda hoje, pode se mostrar frutífera para uma renovação da teoria crítica. Uma visão diferente acerca da relação entre o jovem Horkheimer e a obra de Lukács é desenvolvida em JAY, M. "Max Horkheimer and the Retreat from Hegelian Marxism" (p. 196-202): Jay defende que a influência de Lukács (e Karl Korsch) sobre Horkheimer e os demais pesquisadores agrupados em torno do Instituto tem como fio condutor o conceito de "totalidade"; o mesmo autor aponta, contudo, que essa apropriação não se dá sem ambiguidades: a introdução da psicologia social e das pesquisas sociais empíricas são um fator tanto de aproximação quanto de distanciamento com relação ao paradigma do marxismo ocidental estabelecido por Lukács. Thomas McCarthy também localiza a relação ambígua de Horkheimer com o legado lukácsiano nas distintas concepções de totalidade desenvolvidas por cada autor. No caso de Horkheimer trata-se, coerentemente com sua constante preocupação em não subsumir o particular no universal, de uma totalidade aberta, sempre cambiante: as grandes narrativas da teoria crítica "are never finished but have to be constructed, deconstructed, and reconstructed in ever-changing circumstances" (MCCARTHY, T. "The Idea of a Critical Theory and Its Relation to Philosophy", p. 140). 
Limiar - vol. $1, \mathrm{n}^{\mathrm{o}} 2-1^{\circ}$ semestre 2014

Rupturas e continuidades com relação à crítica lukácsiana da reificação

De saída, é preciso notar que para Horkheimer - assim como para Lukács - a reificação é um elemento crucial na caracterização da sociedade capitalista moderna, na qual os processos sociais, apesar de engendrados pelos próprios atores sociais, aparecem para eles como frutos de forças estranhas. ${ }^{38}$ Além disso, a perda paulatina de uma imagem unitária da sociedade e o processo correspondente de especialização crescente do conhecimento estão, para ambos, conectados a uma racionalidade cada vez mais fragmentária e sem conteúdo, em que pese os sujeitos se encontrarem sob uma dominação fortemente articulada em seu conjunto. Horkheimer dá continuidade, assim, à combinação iniciada por Lukács entre um marxismo centrado na análise dialética da reificação, de um lado, e de outro uma crítica de inspiração weberiana (e simmeliana) da forma de racionalidade que vai de par com o desenvolvimento capitalista na modernidade. ${ }^{39}$

38 HORKHEIMER, M. TTTC, p. 136.

39 A crítica radical da razão, que se tornou a marca mais reconhecível do projeto teórico de Horkheimer e Adorno, contudo, apenas será formulada no exílio americano, a partir da década de 1940 (com a publicação da Dialética do esclarecimento e do Eclipse da razão), período no qual o pensamento de Horkheimer aproxima-se ainda mais das ideias (de caráter mais pessimista) defendidas por Adorno. Na década de 1930, entretanto, há importantes diferenças entre os dois autores: o que para Adorno era a destruição da razão, para Horkheimer, ao contrário, representava uma regressão temporária e socialmente condicionada da razão (cf. BONß, W. "The Program of Interdisciplinary Research and the Beginnings of Critical Theory"). Daí a ideia de um eclipse da razão, e não a de uma dialética que lhe é imanente, como Horkheimer defenderia mais tarde juntamente a Adorno (certamente, tampouco se trata aqui de uma destruição da razão, como lê-se no 
Essa combinação dá tônica, por assim dizer, às reflexões de ambos os autores.

Há, no entanto, pelo menos um aspecto sobre o qual os dois teóricos discordam de modo decisivo: o sujeito ao qual caberia tanto o conhecimento da realidade social quanto a superação de sua existência reificada. Para Lukács, como vimos, somente o proletariado, devido à sua posição no processo de produção do capital e de reprodução material da sociedade, tem a possibilidade de acessar o mundo social a partir do ponto de vista da totalidade -0 único que permitiria um conhecimento "correto", e revolucionário, da realidade social. Segundo a visão de Horkheimer, em contraste, não é a posição social do sujeito do conhecimento que diferencia a teoria crítica das teorias tradicionais: "Tampouco existe uma classe social em cujo consentimento se possa basear. A consciência de qualquer camada na situação atual pode reproduzirse e corromper-se por mais que, devido a sua posição dentro da sociedade, seja destinada à verdade" ${ }^{40}$ É feita claramente nesse trecho uma alusão crítica, mesmo que não nomeada, à defesa lukácsiana do proletariado como sujeito histórico destinado ao conhecimento e à transformação do mundo social. Tendo sofrido uma intensa diferenciação interna na sua estrutura, a classe trabalhadora revela nesse momento uma oposição ainda maior entre os interesses pessoais individuais e os interesses coletivos de classe, de modo que a simples sistematização dos conteúdos de consciência do proletariado conformaria "uma teoria tradicional caracterizada por uma problemática peculiar" e não, como seria de se supor, a "face intelectual do processo histórico de emancipação

título do livro de Lukács de 1954).

40 HORKHEIMER, TTTC, p. 162 
do proletariado". Por outro lado, Horkheimer igualmente descarta o recurso ao partido revolucionário como repositório da "verdadeira" consciência de classe, a ser transmitida e ensinada ao proletariado - o sujeito revolucionário que não tem as condições subjetivas de realizar, por si só, a tarefa histórica que lhe cabia. ${ }^{41}$

Sendo assim, se o pertencimento a uma classe não traz garantia alguma da possibilidade de um conhecimento não reificado, o teórico não pode se furtar a fazer oposição às massas sempre que julgar necessário; do contrário, diz Horkheimer, caise numa "dependência escrava da situação vigente". ${ }^{42}$ Há aqui,

41 Ibid., p. 143. Horkheimer critica, nesses momentos, uma forma bastante simplificada da argumentação lukácsiana sobre o proletariado enquanto sujeito do conhecimento e da práxis revolucionária. O filósofo húngaro defende que essa classe tem o potencial para o conhecimento não reificado da realidade, o que não significa, evidentemente, que esse conhecimento já esteja dado, empiricamente, em todos os membros do proletariado. Essa espinhosa questão é desenvolvida no ensaio "Consciência de classe" (in: HCC, p. 133-191) por meio da distinção entre a consciência de classe psicológica (a consciência empírica de cada proletário ou mesmo do conjunto da classe trabalhadora em um determinado momento histórico) e a consciência de classe atribuída ou imputada (zugerechnet, também traduzida como "adjudicada"; trata-se da consciência que corresponde aos "pensamentos e os sentimentos que os homens teriam tido numa determinada situação da sua vida, se tivessem sido capazes de compreender perfeitamente essa situação e os interesses dela decorrentes, tanto em relação à ação imediata, quanto em relação à estrutura de toda a sociedade conforme a esses interesses", p. 141, grifos do autor). Se Lukács tende cada vez mais, ao longo de sua trajetória, a ver no partido revolucionário a possibilidade de trazer essa "consciência atribuída" à tona, vários dos textos de História e consciência de classe podem ser interpretados segundo uma chave de leitura não vanguardista, com clara influência do pensamento de Rosa Luxemburgo. Sobre essa "tensão" no pensamento de Lukács nesse período cf. NOBRE, M. Lukács e os limites da reificação: um estudo sobre História e consciência de classe; cf. também a recente discussão sobre o tema no capítulo final de MEDEIROS, J. Crítica imanente como práxis.

42 HORKHEIMER, TTTC, p. 143. 
portanto, uma separação entre o teórico crítico e o destinatário dessa teoria, separação que permite a Horkheimer distanciar-se com mais facilidade de concepções simplistas e mecanicistas da consciência de classe, que a veem como uma determinação direta e imediata das condições objetivas da classe social. Ao mesmo tempo, essa separação permite a Horkheimer tanto fundamentar a necessidade de uma teoria crítica da sociedade (já que a consciência empírica dos oprimidos não desemboca espontânea e automaticamente em uma crítica das relações de opressão) quanto colocar a si mesmo como teórico crítico, com interesse na emancipação. ${ }^{43}$

Ora, se de um lado os explorados e o teórico cuja atividade intelectual visa a eliminar a exploração já não coincidem no mesmo sujeito, de outro, porém, eles não podem estar apartados de forma radical, pois o próprio pensamento teórico "faz parte do desenvolvimento das massas como um elemento crítico e estimulador". ${ }^{44} \mathrm{O}$ teórico crítico e as massas exploradas estão numa relação recíproca em que a atividade de um influencia a do outro: o papel do teórico que se pretende crítico consiste, então, para Horkheimer, em "introduzir essa tenacidade [da possibilidade da emancipação] nos grupos mais avançados das camadas dominadas". ${ }^{45}$

43 Ibid., p. 148

44 Ibid., p. 143.

45 Ibid., p. 147. É notória, contudo, a discordância de Horkheimer (e dos demais membros do Instituto) com relação à sociologia do conhecimento de Karl Mannheim, que postulava a ideia dos intelectuais como a "classe" privilegiada para um conhecimento não ideológico das relações sociais. Cf. sobre isso a resenha de Horkheimer ("Ein neuer Ideologiebegriff?") sobre Ideology and Utopia, de Mannheim; cf. também a discussão presente em JAY, "Max Horkheimer and the Retreat from Hegelian Marxism", na qual o autor destaca que, tendo criticado tanto o próprio proletariado e o partido que o representa quanto a ("free-floating") 
Diagnóstico do tempo: o bloqueio das forças emancipatórias

Tal distanciamento com relação à teoria lukácsiana remonta à alteração das condições sociais sob as quais se dá a produção intelectual horkheimeriana: observam-se numerosas transformações desde o momento revolucionário que inspirou Lukács, dentre as quais se destacam a identificação de uma tendência autoritária do operariado alemão e a ascensão do fascismo e do nazismo na Europa, além da diferenciação interior e da complexificação estrutural das classes sociais "tradicionais"; o desenvolvimento de meios de comunicação de massa com um efeito que se supõe domesticador; e, por fim, a separação entre a posse jurídica e o controle dos meios de produção, o que teria como consequência a redução do número de pessoas que detêm realmente o poder, a ponto de a ideologia passar a poder ser elaborada conscientemente. ${ }^{46}$ Todas essas são transformações que têm como consequência a eliminação paulatina de todo movimento de contestação; posteriormente, elas levarão Horkheimer a aprofundar ainda mais o pessimismo relativo à possibilidade de uma prática política emancipatória.

Essa tendência aponta para um bloqueio na possibilidade de superação da dominação capitalista em geral, e em especial por meio da ação organizada da classe operária nos moldes clássicos

intelligentsia como os sujeitos epistemologicamente privilegiados do conhecimento e da transformação histórica, Horkheimer fala em "teóricos que têm um interesse na emancipação" (HORKHEIMER, M. "Traditional and Critical Theory”, p. 241). Cf. também MCCARTHY, T. "The Idea of a Critical Theory and Its Relation to Philosophy", p. 146.

46 HORKHEIMER, TTTC, p. 158. Cf. também as transformações destacadas por DUBIEL, H. Theory and Politics, p. 99-100. 
do marxismo que influenciaram o modelo lukácsiano. Se a práxis, tal como concebida até então, encontra-se bloqueada, só resta a teoria como último bastião da resistência, agora refugiada naqueles que têm interesse na transformação, não sendo mais uma prerrogativa do proletariado "por mais que [este] sofra na própria carne o absurdo da continuação da miséria e do aumento da injustiça". ${ }^{47}$

Para formular esse diagnóstico do tempo presente, Horkheimer contou com a corroboração das pesquisas empíricas e teóricas realizadas por diversos profissionais no Instituto de Pesquisa Social na década de 1930. Um exemplo são os Estudos sobre autoridade e família (de 1936), de autoria de Horkheimer, Erich Fromm, Herbert Marcuse e uma série de outros pesquisadores (que procuraram evidenciar, entre outras coisas, uma tendência autoritária do operariado alemão) $;{ }^{48}$ ou ainda a análise de Friedrich Pollock acerca da estabilização dos elementos autodestrutivos do capitalismo a partir da crescente atuação do Estado na economia e da formação de grandes monopólios (o que teria posto fim à fase liberal do capitalismo e permitido uma administração cada vez mais completa de todos impulsos vitais dos sujeitos). ${ }^{49}$

47 HORKHEIMER, TTTC, p. 142-143.

48 HORKHEIMER, M; FROMM, E; MARCUSE, H. et alli, Studien über Autorität und Familie (esses três autores foram responsáveis, respectivamente, pela "Parte geral", "Parte de psicologia social" e "Parte de história das ideias").

49 As análises em torno do conceito de "capitalismo de Estado", que constituem a contribuição mais importante de Pollock para o desenvolvimento da teoria crítica no âmbito do Instituto de Pesquisa Social, foram sintetizadas em um artigo de 1941 ("State Capitalism"). Pollock já vinha há tempos, entretanto, trabalhando em estreita colaboração com Horkheimer e tais investigações vinham sendo publicadas na revista do Instituto desde 1932 (cf. POLLOCK, F. "Die gegenwärtige Lage des Kapitalismus und die Aussichten einer planwirtschaftlichen Neuordnung"; sobre 
É em estreita conexão com esse diagnóstico - e com as decorrentes rupturas com respeito às ideias aventadas por Lukács no início da década de 1920 - que Horkheimer articula, quase duas décadas mais tarde, o modelo de teoria crítica que tornou-se referência para as gerações seguintes dessa corrente de pensamento. Deixando de lado os elementos da descrição lukácsiana da realidade social que não são mais considerados plausíveis, Horkheimer mantém de modo reformulado as intuições centrais da interpretação lukácsiana do legado hegelomarxiano como uma teoria dialética - que passa, a partir de então, a ser chamada de crítica.

\section{Princípios da teoria crítica}

A maneira segundo a qual Horkheimer reformulou essas intuições nos anos 1930 - e especialmente o ensaio publicado em 1937 na revista do Instituto - tornou-se uma referência duradoura (poder-se-ia até dizer "canônica") para as distintas vertentes da teoria crítica. Esta é delineada no texto de Horkheimer em boa medida por oposição à "teoria tradicional" representada pelos diferentes matizes do fazer científico da época cuja representação é a de um "saber acumulado de tal forma que permita ser este utilizado na caracterização dos fatos tão minuciosamente quanto possível". ${ }^{50}$ E mais: Horkheimer observa que mesmo as ciências humanas estabelecidas - tanto as empíricas, meramente descritivas, quanto as teóricas, que procuram formular princípios

isso cf. também RUGITSKY, F. "Da crítica da crise à crise da crítica? Uma leitura da obra de Friedrich Pollock", p. 5).

50 HORKHEIMER, TTTC, p. 125. 
abstratos gerais ${ }^{51}$ - estão cada vez mais seguindo os moldes das ciências naturais, que por sua vez se inspiram nas matemáticas. Assim como ocorre nestas últimas, as teorias sociais tradicionais se veem numa relação de oposição com o seu objeto - a sociedade -, como se não fizessem parte, desde o início, dos processos sociais que buscam descrever ou explicar.

Deste modo, um eixo fundamental de diferença entre a teoria crítica e a teoria tradicional reside na reflexividade da investigação social. As ciências sociais que se miram nas naturais consideram a si mesmas como ciências sem pressupostos e relegam as demais abordagens à condição de pré-científicas, ideológicas ou auto-interessadas. ${ }^{52}$ Assim, uma das primeiras tarefas da teoria crítica consiste, para Horkheimer, em desmascarar essa "não posição" do conhecimento científico da sociedade e mostrar seu papel e seu enraizamento em determinada ordem social. Com isto, Horkheimer não pretende descreditar completamente os resultados das teorias sociais tradicionais, mas revelar, de acordo com a proposta hegeliana, sua profunda historicidade. ${ }^{53}$

51 Não há, contudo, entre as ciências tradicionais empíricas e teóricas uma diferença na estrutura do pensamento. Para Horkheimer, existe uma tendência interna à crise da ciência burguesa moderna, crise cuja origem reside no conflito entre "ciência empírica" (positivismo) e "filosofia social especulativa" (metafísica): ambas têm sua razão de ser, mas a bifurcação histórica entre elas e sua absolutização em formas fixas acaba por transformar suas preocupações legítimas em ideologia (cf. BONß, "The Program of Interdisciplinary Research").

52 MCCARTHY, "The Idea of a Critical Theory and Its Relation to Philosophy". 53 É importante notar, para a discussão atual, que Horkheimer "[...] did not regard the deconstruction of allegedly disembodied social knowledge as entailing the delegitimation of empirical social research as such. On the contrary, processing and deploying vast bodies of 'factual' knowledge is a requirement of any developed society" (MCCARTHY, "The Idea of a Critical Theory and Its Relation to Philosophy", p. 136). O problema surge apenas com a sua absolutização. 
É central para essa perspectiva a ideia de que a ciência jamais é neutra: ela depende sempre de sua inserção na reprodução social como momento do processo de divisão do trabalho. O sujeito do conhecimento e o sujeito que age não podem ser pensados de maneira isolada: toda ciência é uma formação cultural do tempo presente, e isso traz consequências teóricas, como a necessidade de tematizar esse presente como objeto da própria ciência. A teoria tradicional, contudo, não é reflexiva o suficiente: não pensa teoricamente sobre a sua posição e função social e não pode, portanto, reconhecer que "tanto quanto a influência do material sobre a teoria, a aplicação da teoria ao material não é apenas um processo intracientífico, mas também um processo social". ${ }^{54} \mathrm{Sem}$ essa reflexão, a única atividade que resta à teoria tradicional é pintar um quadro o mais detalhado e coerente possível da realidade social, ainda que esta seja terrível. ${ }^{55}$

Se é assim, se essa teoria toma os processos sociais como dados, do mesmo modo como são dados externamente os processos naturais analisados pelas ciências "duras", ela não pode senão confirmar o existente. Já que não pode haver, segundo Horkheimer, nenhuma teoria neutra, indiferente a seu momento histórico, ou isenta de interesses (inclusive políticos), a hipóstase desse tipo tradicional de teoria como autônomo em relação às condições sociais sob as quais foi produzido - e, mais do que isso: como o único tipo de teoria possível - faz com que ela decaia ao nível da ideologia. ${ }^{56}$

A teoria tradicional, portanto, desempenha uma função

54 HORKHEIMER, TTTC, p. 130.

55 Ibid., p. 132.

56 Ibid., p. 129. 
social de manutenção das relações de poder existentes, mesmo que não thes seja diretamente produtiva; ${ }^{57}$ a teoria crítica, ao contrário, exige uma atitude orientada para a emancipação. Esse comportamento tem que se expressar, porém, em uma conexão interna com o próprio proceder teórico, diferentemente da teoria tradicional pragmática, que, de fato, considera vital o entrelaçamento entre conhecimento e condições sociais, mas o faz de forma não orgânica, mediante a aplicação exterior (e posterior) do conhecimento à realidade, visando a melhorias nas condições sociais: "O material em fatos, a matéria, é fornecida de fora. A ciência proporciona uma formulação clara, bem visível, de modo que se possam manusear os conhecimentos como se queira. [...] O dualismo entre pensar e ser, entendimento e percepção lhe é natural" ${ }^{58}$ Contrariamente a esse modo de proceder, tanto a aplicação dos conhecimentos da teoria crítica aos dados da realidade social quanto a própria produção de tais conhecimentos só podem ser compreendidas a partir de sua conexão dinâmica com os processos sociais reais. Dessa forma, a exposição crítica das contradições da realidade não só expressa uma situação histórica, mas simultaneamente é fruto dela e, mais além, atua de volta sobre ela. ${ }^{59} \mathrm{~A}$ ciência, portanto, não tem apenas um contexto cognitivo, mas também social.

O ir além da superfície cristalizada dos fatos observados (tomados, então, não como dados, mas como configurações históricas que surgem e se transformam ao longo do tempo e a partir da ação humana); o ato de revelar, a partir de um ponto de vista

57 Ibid., p. 130-131.

58 Ibid., p. 131.

59 Ibid., p. 144. 
orientado para a emancipação, as possibilidades não realizadas que os "fatos" inopinadamente contêm - tal é a dimensão da transcendência, um elemento indispensável para uma teoria que se pretende crítica. Essa dimensão normativa fornece os critérios para uma determinada organização dos dados da experiência ao mesmo tempo em que é deles extraída: na formulação sintética de Bonß, "Facts are facts only in the context of theoretical interpretations, and the further development of theories depends on empirical investigation". ${ }^{60}$ Daí que a ciência da sociedade deva ser tomada como unidade entre trabalhos empíricos e teóricos.

Como na obra seminal de Lukács, aqui tampouco pode a dimensão normativa levar a teoria crítica à utopia: o teórico crítico deve poder identificar, por meio de um diagnóstico do tempo presente, as tendências para a emancipação na própria situação atual. Assim, para Horkheimer, a orientação da teoria crítica para uma sociedade emancipada, uma associação de homens livres, "se diferencia da utopia pela prova de sua possibilidade real fundada nas forças produtivas humanas desenvolvidas". ${ }^{61}$ Em outras palavras: a teoria não deve criar modelos ideais de sociedade em nome dos quais a crítica à realidade seria feita; ela tem que ser capaz de divisar na realidade mesma os potenciais emancipatórios que ainda não foram desenvolvidos, ou o foram apenas parcialmente. A emancipação, para não ser utópica, deve ter seu germe inscrito no real como uma força atuante na história, como "uma imagem do futuro surgida da compreensão profunda do presente". ${ }^{62}$

60 BONß, "The Program of Interdisciplinary Research", p. 101.

61 HORKHEIMER, TTTC, p. 146.

62 Ibid., p. 147. 
Assim, de forma similar ao que ocorre em História e consciência de classe, Horkheimer defende que é preciso trabalhar inicialmente com os conceitos que já estão em operação nos saberes existentes - inclusive, portanto, na teoria tradicional. Consequentemente, para que sejam negados de forma não abstrata, tais conceitos têm que ser inicialmente reconhecidos ao menos como operantes. Essa recusa a criar um arcabouço categorial distanciado a realidade é uma característica central do materialismo da teoria crítica: "As an alternative conception of science, it [critical theory] refers to a cognitive and social learning process that goes beyond the principle of returning to material states of affairs. It begins with the achievements of the bourgeois sciences, transcends them, and leads to a more comprehensive form of constituting and appropriating reality". ${ }^{63}$

Certamente tal afirmação dos conceitos provindos da teoria tradicional tem que ser, a um só tempo, a sua negação: "Por outro lado, aceitar isso simplesmente aparece como uma inverdade torpe: o reconhecimento crítico das categorias dominantes na vida social contém ao mesmo tempo a sua condenação". ${ }^{64} \mathrm{~A}$ vantagem do projeto crítico defendido por Horkheimer reside na possibilidade de conectar reflexivamente uma crítica filosófica da razão e modos de pesquisa desenvolvidos nas ciências humanas; é nesse sentido que Horkheimer caracteriza a teoria crítica como uma "interpenetração dialética contínua" entre filosofia e pesquisa empírica, como uma forma de "investigação social filosoficamente orientada". ${ }^{65}$

63 BONß, "The Program of Interdisciplinary Research”, p. 105.

64 HORKHEIMER, TTTC, p. 138-139.

65 Cf. HORKHEIMER, "The State of Contemporary Social Philosophy...”. 
Torna-se possível, então, compreender que a distinção entre teoria crítica e teoria tradicional não implica, em sua formulação horkheimeriana (assim como na lukácsiana), que a segunda deva ser descartada como mera ideologia. Primeiramente, porque ela é necessária para a reprodução social e deve ser desenvolvida ao máximo para a compreensão e a dominação da natureza; ${ }^{66}$ e em segundo lugar porque, na medida em que o saber tradicional pertence à totalidade social, ele já está, de saída, contido na teoria e na práxis crítica. ${ }^{67}$ Bonß conecta esse modo de proceder com a noção de "superação" (Aufhebung) em Marx, que significa ao mesmo tempo crítica e apropriação: Horkheimer vê a relação dialética entre filosofia e ciência como algo que eleva o conhecimento a um nível superior. ${ }^{68}$

Nesse sentido, as ciências especializadas que constituem a teoria tradicional mais avançada fornecem a base, por assim dizer,

66 HORKHEIMER, TTTC, p. 144. Impossível não perceber aqui a analogia com respeito tanto ao posicionamento de Marx acerca do desenvolvimento necessário das forças produtivas quanto ao de Habermas sobre a inevitabilidade da racionalidade instrumental para a reprodução material da sociedade.

67 Ibid., p. 161 e 147, respectivamente. Ao contrário da desconstrução e de outras abordagens anti-racionalistas, o projeto da teoria crítica dos anos 1930 permite uma reconstrução crítica das concepções iluministas da razão e do sujeito racional: trata-se de uma espécie de negação determinada, na qual tais concepções são recolocadas em formas sócio-históricas em lugar de serem simplesmente descartadas. Nesse sentido, Horkheimer insiste que os teóricos críticos não devem abandonar os ideais universalistas do esclarecimento às forças regressivas, mas sim reapropriá-las criticamente para propósitos progressistas na medida em que desmascaram as distorções específicas dos conceitos e os transformam de modo a não serem mais apropriáveis para a justificação da injustiça e da opressão (HORKHEIMER, "Ein neuer Ideologiebegriff?”; cf. também HORKHEIMER, "Materialism and Morality", p. 37 e MCCARTHY, "The Idea of a Critical Theory and Its Relation to Philosophy").

68 BONß, "The Program of Interdisciplinary Research". 
sobre a qual a teoria crítica progride.$^{69}$ Esta possui, de acordo com Horkheimer, uma "profunda compreensão" dos passos isolados da teoria tradicional, de forma a mostrar que eles "podem ser importantes para qualquer finalidade, inclusive para a teoria crítica". Os exemplos de Horkheimer são a sociologia descritiva e a estatística, que, apesar de serem frutos do pensamento meramente registrador, podem ser apropriadas e tornadas úteis no âmbito de uma investigação crítica. ${ }^{70}$ Isso se torna possível pela manutenção da categoria da totalidade social no horizonte teórico de Horkheimer, a partir da qual é possível identificar um sentido para a concatenação necessária dos saberes especializados que, de resto, são limitados e parciais. ${ }^{71}$

\section{O programa do materialismo interdisciplinar}

É nesse contexto geral que podemos compreender o projeto horkheimeriano de um materialismo interdisciplinar, formulado em inícios da década de $1930 .{ }^{72}$ Assim como Lukács, Horkheimer

69 HORKHEIMER, TTTC, p. 156.

70 Ibid., p. 154 e 162, respectivamente.

71 Ibid., p. 132.

72 É preciso fazer aqui a ressalva de que as posições de Horkheimer no início da década de 1930, quando formula o programa do materialismo interdisciplinar, não são exatamente as mesmas que aparecem no texto "canônico" de 1937. Helmut Dubiel, em seu estudo clássico sobre as fases iniciais da teoria crítica (cf. DUBIEL, Theory and Politics), aponta que já no final dos anos 1930 o próprio Horkheimer já não defendia o projeto interdisciplinar, de forma que os pesquisadores do Instituto já não se orientavam por ele . Não há consenso entre os comentadores, entretanto, acerca do conteúdo e da dimensão dessa modificação. O que importa, aqui, são as muitas continuidades entre esse dois momentos e, principalmente, a ideia de que a concepção e a experiência do programa interdisciplinar foram uma etapa fundamental no trajeto intelectual que levou a "Teoria tradicional e teoria crítica". 
considera que a crescente especialização das ciências e a perda da imagem da totalidade social, fenômenos que surgem sob as condições atuais da divisão do trabalho, são altamente prejudiciais para a compreensão do funcionamento da sociedade e das possibilidades de sua transformação. Ao contrário de Lukács, no entanto, Horkheimer propõe que as pesquisas especializadas sejam elas levadas a cabo por teóricos tradicionais ou por aqueles interessados na emancipação - tomem parte sistematicamente na construção do saber crítico. ${ }^{73}$ Afinal, diz o autor, a teoria crítica tem "como pressuposto a totalidade do saber disponível e a assimilação do material adquirido através da pesquisa própria ou de outrem". ${ }^{74}$ Mais do que isso: Horkheimer propõe que os teóricos críticos se engajem ativamente na elaboração e aplicação de pesquisas especializadas de cunho eminentemente empírico.

O programa interdisciplinar de pesquisa proposto por Horkheimer para o Instituto previa que fosse selecionado um conjunto significativo de saberes centrados no presente histórico e que, por meio da sua cooperação, a linha divisória entre as ciências humanas sofresse deslocamentos que provocassem, assim, uma renovação no tema da especialização científica. ${ }^{75}$ Isso resultou na colaboração de pesquisadores de várias áreas do

73 Cf. NOBRE, M., Lukács e os limites da reificação (especialmente as p. 109 ss. das "Considerações finais").

74 HORKHEIMER, TTTC, p. 151 (grifos M. T.).

75 Cf. sua fala inaugural em 1931 como diretor do Instituto de Pesquisa Social: HORKHEIMER, "The Present Situation of Social Philosophy and the Tasks of an Institute for Social Research". Bon $\beta$ destaca que o materialismo interdisciplinar foi concebido como uma forma produtiva de lidar com as aporias do conhecimento científico mencionadas anteriormente, que não podem ser resolvidas, mas "administradas" (managed) por meio da organização da ciência (BONß, "The Program of Interdisciplinary Research"). 
conhecimento, tais como sociologia, direito, história, psicologia social e psicanálise, economia, ciência política, estética e filosofia da arte, entre outras. Para conectar os resultados parciais dessas disciplinas, Horkheimer defende um processo de coordenação da estratégia de pesquisa que começa com a filosofia social e suas suposições gerais sobre a estrutura e desenvolvimento da totalidade social - algo que não pode exigir, de saída, cientificidade, mas que aparece com uma demanda por universalização baseada na experiência pré-científica. ${ }^{76}$ Essa demanda pode ser reformulada cientificamente na medida em que as suposições são "testadas" com sucesso nos campos da economia, da psicologia social e das ciências da cultura. ${ }^{77}$

Nesse contexto, a interdisciplinaridade significava que cada profissional deveria proceder com intenção crítica tanto na interpretação dos resultados das pesquisas realizadas por teóricos tradicionais em sua respectiva área de atuação quanto na implementação de investigações empíricas próprias. O que garantiria o caráter crítico dessas interpretações e investigações especializadas é o fato de que elas são sempre remetidas, desde

76 A "filosofia social" de que fala Horkheimer não pode ser igualada nem à sociologia, nem à filosofia puras. Nas palavras de Martin Jay: "Social philosophy was thus more than a single specialized discipline, such as sociology. It inherited the traditional philosophical impulse to know the whole. It ought not, however, to be confused with philosophy pure and simple, which normally remains hostile to 'mere', empirical research". Ele acrescenta: "In other words, the abstract antithesis between totalistic philosophy and analytic empirical research had to be transcended" (JAY, M. "Max Horkheimer and the Retreat from Hegelian Marxism", p. 199).

77 Nas palavras de Wolfgang Bonß: "The 'prescientific' status of social philosophy already indicates the importance of social research. Its task is to transfer the 'big questions' into the standards of the individual disciplines and treat them comprehensively with the available methodological tools" (BONß, W. "The Program of Interdisciplinary Research", p. 114-115). 
o início, a uma concepção do conjunto dos processos sociais como uma totalidade - e uma totalidade cujo centro atribuidor de sentido consiste, na esteira de Marx, em uma análise crítica da forma das relações capitalistas atuais. Para Horkheimer, importa estabelecer internamente uma conexão entre, por um lado, (I) as relações econômicas desveladas pela (crítica da) economia política e, por outro, (II) o campo das manifestações culturais e (III) o processo de formação das estruturas de personalidade os dois últimos analisados pelas demais disciplinas específicas, que ganham ou perdem relevância relativa conforme as condições sociais o exigirem. ${ }^{78}$ Com essa dinâmica, Horkheimer procura criar as condições para uma pesquisa teórico-social com intenção normativa, produzida a partir de um vínculo orgânico, e não de uma justaposição externa, entre elementos empírico-descritivos e filosófico-normativos:

The relation between philosophical and corresponding specialized scientific disciplines cannot be conceived as though philosophy deals with the really decisive problems in the process constructing theories beyond the reach of the empirical sciences, its own concepts of reality, and systems comprehending the totality - while on the other side empirical research carries out its long, boring, individual studies that split up into a thousand partial questions, culminating in a chaos of countless enclaves of specialists. ${ }^{79}$

Esse modelo precisa ser substituído por uma forma dialética

78 HORKHEIMER, M. “The Present Situation of Social Philosophy”, p. 12. 79 Ibid., p. 9. 
de interconexão entre filosofia e pesquisa social, na medida em que a primeira "é capaz de fornecer impulsos estimulantes, e ao mesmo tempo permanece aberta o suficiente para se deixar ser influenciada e modificada por esses estudos concretos". ${ }^{80}$ As questões filosóficas são assim integradas no processo de pesquisa empírica, e vice-versa.

Isso não pode ser levado a cabo, entretanto, por um único indivíduo, em razão do extenso volume do material disponível e da diversidade dos saberes especializados imprescindíveis; daí o caráter fortemente coletivo do projeto horkheimeriano. Afinal, é absolutamente decisivo não perder de vista o contexto mais amplo.

O programa delineado por Horkheimer para o Instituto de Pesquisa Social nunca chegou a ser plenamente realizado. Especialmente a partir da década de 1940, esse programa foi dando lugar a projetos teóricos que geralmente careciam desse otimismo (ainda que relativo) com respeito aos limites e às possibilidades críticas das pesquisas no campo das ciências sociais.

Ainda assim, algumas pesquisas empíricas relevantes foram feitas tanto antes quanto depois da emigração da maior parte dos membros do Instituto para os EUA.$^{81}$ Além disso, e mais importante, na volta para a Alemanha, "the institute did important

80 HORKHEIMER, "The Present Situation of Social Philosophy”, p. 10 (tradução M. T.). 81 Destacam-se aqui The Working Class in Weimar Germany: a Psychological and Sociological Study, investigação conduzida por Erich Fromm em 1929; The Authoritarian Personality, pesquisa conjunta de Adorno et alli publicada em 1950 e os demais "Estudos sobre o preconceito" que Horkheimer passou a organizar a partir de 1945 nos EUA; além dos citados Studien über Autorität und Familie, de Horkheimer, Fromm, Marcuse et alli. Sobre as pesquisas empíricas do Instituto de Pesquisa Social, além dos trabalhos já citados cf. também BONß, "Kritische Theorie und empirische Sozialforschung. Anmerkungen zu einem Fallbeispiel"; BONß; SCHINDLER, "Kritische Theorie als interdisziplinärer Materialismus". 
work: it contributed to the reestablishment of social research in Germany, promoting the introduction of new techniques in the social sciences while trying to keep alive the connection with 'the great tradition of European philosophy and sociology"', 82 Ou seja: foi aberta desse modo uma via para a colaboração não só entre teoria crítica e teoria tradicional, mas também entre pesquisa social empírica e análise teórica normativa, no que foi chamado de uma "combinação única entre filosofia e pesquisa empírica". ${ }^{83}$ Ao menos na década de 1930, portanto, Horkheimer rejeita seja o desacoplamento entre filosofia normativa e teoria social especializada, seja a sua interligação apenas exterior e artificial; ele defende, além disso, que os próprios representantes da teoria crítica se engajem na produção ativa de saberes científicos específicos acerca da realidade social, como forma de perseguir uma interpenetração recíproca e orgânica entre ambos os momentos da atividade intelectual crítica. Nas palavras de Horkheimer: "Dialectics, too, notes empirical material with the greatest care. The accumulation of solitary facts can be most incisive if dialectic thought manipulates them. Within dialectical theory such individual facts always appear in a definite connection which enters into every concept and which seeks to reflect reality in its totality". ${ }^{84}$

Essa maneira de proceder foi caracterizada por Dubiel em seu já citado estudo sobre o Instituto de Pesquisa Social como correspondente, em linhas gerais, à dialética entre os modos de pesquisa e de apresentação (Forschung e Darstellung)

82 BENHABIB, S.; BONß, W.; MCCOLE; J. "Max Horkheimer: Between Philosophy and Social Science", p. 9.

83 BENHABIB; BONB; MCCOLE; "Max Horkheimer: Between Philosophy and Social Science".

84 HORKHEIMER, “The Latest Attack on Metaphysics”, p. 161. 
desenvolvidos por Marx no Capital. ${ }^{85} \mathrm{~A}$ pesquisa referese a investigações concretas conduzidas mediante técnicas sociológicas relativamente tradicionais (um exemplo seriam os surveys empregados na pesquisa sobre os trabalhadores alemães); já a apresentação corresponde a uma "representação" totalizadora dos resultados da pesquisa em uma nova síntese teórica, processo no qual o próprio contexto conceitual e teórico que orientará o trabalho empírico posterior também é transformado. ${ }^{86}$ Assim, embora as descobertas empíricas não fossem tomadas como verificação ou falsificação da teoria no sentido positivista tradicional, elas ajudaram a modificar e enriquecer o projeto crítico dos anos 1930. Ou, pelo menos, assim é que o programa materialista interdisciplinar era teoricamente concebido. A prática, contudo, se mostra mais complicada. Nas palavras de Martin Jay, "The integration of these investigations of various dimensions of the totality was not, of course, without its difficulties, as the dialectic of Forschung and Darstellung proved less smoothly reciprocal in practice than in theory" ${ }^{87}$

$*$

Os motivos para o abandono do projeto materialista interdisciplinar se apresentam em diversos matizes. Enquanto uma parte significativa dos comentadores destaca a importância das intensas transformações sociais e históricas que afetaram

85 Cf. também HORKHEIMER, M. "The Rationalism Debate in Contemporary Philosophy", p. 237.

86 Cf. também JAY, "Max Horkheimer and the Retreat from Hegelian Marxism”, p. 199. 87 Ibid., p. 200-201. 
o funcionamento do Instituto nas turbulentas décadas de 1930 e 1940, a interpretação de autores como Wolfgang Bonß e Thomas McCarthy tem a vantagem de sublinhar que a revisão do materialismo interdisciplinar realizada no fim dos anos 1930 não se deve apenas ou eminentemente a uma mudança nas circunstâncias históricas, mas revela deficiências teóricas internas cuja tematização é fundamental para que uma atualização da teoria crítica não se apoie na reconstrução do passado como mito.

ParaBonß, ogrande problema consiste em que a superação das aporias que Horkheimer identifica no desenvolvimento da ciência moderna (isto é: o caráter fragmentário da ciência e a oposição entre positivismo e metafísica) não ocorre automaticamente uma vez que representantes de várias disciplinas se juntam em um coletivo que procura solucionar problemas fazendo em comum o que os demais pesquisadores sempre fizeram isoladamente. Isso porque o trabalho de cada disciplina permanece inalterado: "In the end, the interdisciplinary claim amounts to no more than an external formula for integration, a view that is certainly vulnerable to objections". ${ }^{88}$ As transformações exigidas no campo teórico podem ser realizadas apenas quando se vai além do mero trabalho colaborativo de várias disciplinas especializadas e é promovida, assim, uma interação que propicia um movimento de transcendência das próprias disciplinas. ${ }^{89} \mathrm{Sem}$ isso, acrescenta Bonß, o termo "pesquisa interdisciplinar" perde muito de sua conotação crítica e o que resta é uma confiança, até certo ponto ingênua, na dinâmica procedimental-transformativa dos grupos de trabalho interdisciplinares. Segundo essa interpretação, a crise

88 BONß, “The Program of Interdisciplinary Research", p. 118. 89 Ibid., p. 118-119. 
da ciência está calcada em uma crise profunda dos seus métodos, de forma que a superação das aporias descritas por Horkheimer exigiria o desenvolvimento de uma metodologia alternativa inteiramente diversa desde o início (e não apenas na integração posterior em uma totalidade dialética), o que não ocorreu..$^{90}$

Já Thomas McCarthy ${ }^{91}$ enumera, em uma interpretação bastante próxima daquela exposta por Habermas na Teoria da ação comunicativa, uma série de fraquezas - essas mais conectadas ao conteúdo que ao método - presentes no modelo de Horkheimer: a tendência em conceber a sociedade (pelo menos potencialmente) como um sujeito unificado e, portanto, em marginalizar considerações referentes ao pluralismo nos níveis social, cultural e político; a demasiada confiança na crítica marxista da economia política, especialmente na análise de classes, para identificar as causas e condições da injustiça nas ordens sociais existentes; e, por fim, a filiação a uma filosofia da história ou uma "grande metanarrativa" que subestima os papéis da contingência, da localidade e da identidade nas lutas contra a dominação.

90 Para Bonß, a concepção de Horkheimer permanece amplamente convencional: ele não leva em conta que a seletividade das disciplinas especializadas é condicionada pelo modo como elas constituem seu objeto e é continuamente reproduzida no nível metodológico. De fato, Horkheimer defende que a pesquisa social continue aplicando os métodos científicos "mais refinados" (HORKHEIMER, TTTC), de modo que não fica claro como se dá sua integração com a filosofia social: tais "métodos científicos" seriam valorativamente neutros e receberiam uma virada crítica apenas posteriormente? O resultado, afirma Bonß, é uma percepção seletiva das disciplinas individuais: "Notice was taken only of what appeared to be useful for the envisioned explanatory goal. Of interest was less their internal logic (including their respective social-theoretical merits and deficits) than their suitability for being integrated into a theory of the "lost revolution"” (BONß, "The Program of Interdisciplinary Research", p. 121).

91 MCCARTHY, "The Idea of a Critical Theory and Its Relation to Philosophy". 
Essas importantes críticas não eliminam a relevância que a concepção interdisciplinar da pesquisa social mantém na atualidade, "for it attempted to comprehend the course of society as a crisis-ridden nexus of various dimensions that today are still usually described in isolation as different social systems". Mas a mediação desses sistemas (e, portanto, a totalidade social) não podem ser adequadamente apreendidas do modo proposto por Horkheimer: "It would be better to inquire into epistemologically more adequate means for mastering the fundamental aporias, which remain in force". 92

\section{Considerações finais: perspectivas de desenvolvimento}

A atualização dos modelos de Lukács e Horkheimer: limites e potencialidades

O percurso da teoria crítica aqui delineado partiu da perspectivainteressada na interconexão entre as dimensões teóricas imanente-descritiva e transcendente-normativa, representadas, de um lado, pelas teorias da sociedade e investigações empíricas sem propósito crítico, e, de outro, pelo interesse emancipatório que orienta o procedimento teórico em seu conjunto, desde a escolha do objeto de estudo até a seleção e concatenação dos dados da realidade concreta. A reconstrução guiada por tal perspectiva indica como, na vertente teórica que surge a partir das figuras de Lukács e Horkheimer, o vínculo entre as duas dimensões é uma constante - a despeito da contínua reformulação dos modelos críticos - enquanto elemento constitutivo tanto do modo de conceber a teoria crítica quanto da maneira pela qual esses autores

92 BONß, “The Program of Interdisciplinary Research”, p. 122. 
procuram proceder em seus projetos teóricos concretos.

$\mathrm{Na}$ análise lukácsiana da reificação, os elementos de diagnóstico de época fornecidos por representantes do "pensamento burguês" são articulados no interior da perspectiva crítica de origem marxista-dialética, tendo como resultado ao mesmo tempo uma transformação fundamental nas teorias da sociedade apropriadas (como as de Simmel e Weber, rearticuladas no novo contexto materialista) e um deslocamento no interior do próprio quadro crítico de referência (deslocamento representado pela introdução da consciência de classe como categoria-chave para compreender a sociedade capitalista). Tal rearticulação só foi possível na medida em que a ideia de "totalidade" permaneceu no horizonte teórico de Lukács.

Já nos anos 1930, as pesquisas empíricas do Instituto de Pesquisa Social acerca das tendências autoritárias do operariado alemão - para ficar em um exemplo central - levaram Horkheimer a abandonar a ideia lukácsiana do proletariado como sujeito revolucionário por excelência e a elaborar um programa de pesquisa apoiado na colaboração entre diferentes disciplinas no interior de um quadro teórico mais amplo, porém ainda centrado na crítica da economia política. As investigações empíricas no contexto de tal materialismo interdisciplinar foram também, no entanto, reciprocamente informadas, desde o início, pelo ponto de vista crítico e referidas a uma "totalidade dialética".

Para que possamos ir além da identificação desse importante (porque constitutivo) traço comum entre os modelos críticos representados pelo materialismo dialético de Lukács e o materialismo interdisciplinar de Horkheimer, e para que possamos, assim, extrair considerações significativas para um possível e frutífero desdobramento da teoria crítica, é preciso poder identificar brevemente, além disso, os limites relativos a 
cada modelo e seus potenciais de desenvolvimento não exauridos.

Por razões históricas e teóricas, o modelo crítico de Lukács é o que demanda uma maior quantidade de mediações para ser atualizado. Há, não obstante, pelo menos dois fatores que contam a seu favor.

Em primeiro lugar, cabe destacar que a grande realização do filósofo húngaro - articular de forma coerente e produtiva a crítica marxiana da alienação, a crítica weberiana da racionalidade ocidental e a crítica simmeliana das relações monetárias, numa época de grande polarização em que os meios intelectuais de orientação marxista encontravam-se em grande medida presos a uma ortodoxia impermeável às contribuições “burguesas", e viceversa - representa um ganho irreversível para a possibilidade de uma teoria que se pretende ao mesmo tempo crítica e bem informada e fundamentada teoricamente. Hoje, felizmente, já não são levadas a sério objeções fundadas em uma suposta pureza teórica a ser depreendida de um conjunto de teses originárias. Trata-se de um ganho também, portanto, para uma articulação frutífera entre teoria crítica e teoria tradicional.

Em segundo lugar, é preciso pôr em relevo o fato de que a crítica ao fenômeno da reificação tem vivido um reflorescimento nos tempos recentes, especialmente na Alemanha, com a publicação de estudos que têm por meta trazer para a compreensão da sociedade contemporânea essa categoria tão importante para o desenvolvimento da teoria crítica no século passado. ${ }^{93}$

93 Para ficar em apenas alguns exemplos, cf. HONNETH, A. Verdinglichung; JAEGGI, R.; STAHL, T., "Schwerpunkt: Verdinglichung"; STAHL, T. "Verdinglichung als Pathologie zweiter Ordnung"; QUADFLIEG, D. "Zur Dialektik von Verdinglichung und Freiheit"; e JÜTTEN, T. "Verdinglichung und Freiheit". 
Contra a atualização da teoria lukácsiana, entretanto, pesam as duras críticas a ela dirigidas por diversos autores, sendo Habermas um dos mais importantes no próprio campo da teoria crítica. ${ }^{94} \mathrm{O}$ cerne dessas críticas remonta especialmente à procura de um sujeito-objeto-idêntico e à concepção do proletariado como esse macrossujeito agindo na história, além da ligação (mesmo que mediada) entre a posição social de uma classe e sua possibilidade de conhecer sua própria realidade sem o véu da reificação. Acrescente-se a isso o fato de que ideia de uma "totalidade social", central para a crítica lukácsiana da reificação, está longe de gozar de uma posição epistemologicamente segura nas teorias sociais da atualidade. Tampouco é plausível, nos dias de hoje, rejeitar por completo os resultados obtidos em investigações especializadas de cunho sociológico, historiográfico, antropológico, etc.

O mesmo problema afeta o programa interdisciplinar formulado na década de 1930. Apesar de Horkheimer ter abandonado, como vimos, as esperanças lukácsianas de encontrar no proletariado o potencial sujeito-objeto-idêntico da história, é mantida no seu horizonte teórico a categoria da totalidade social como referência decisiva para o procedimento dialético. ${ }^{95} \mathrm{~A}$ fundamentação normativa desse procedimento - hoje considerada uma etapa incontornável do fazer teórico - não é, entretanto, tematizada por Horkheimer, ${ }^{96}$ o que torna mais complexa e

94 Cf. HABERMAS, J. Teoria da ação comunicativa, vol. 1, cap. 4.

95 Sem um conceito forte de totalidade, afirma Voirol, toda a estrutura teórica sobre a qual repousava o programa interdisciplinar desmorona: "Com o colapso da perspectiva revolucionária desapareceu o elemento prático que permitia justificar a ideia de totalidade social - e a possibilidade de sua reconstituição efetiva na prática de um sujeito histórico" (VOIROL, "Teoria crítica e pesquisa social", p. 48).

96 VOIROL, "Teoria crítica e pesquisa social”, p. 95. 
mediada a possibilidade de sua atualização.

Outro ponto problemático do projeto de Horkheimer foi desenvolvido em detalhe por Axel Honneth no primeiro capítulo Kritik der Macht (1986) e diz respeito a um certo funcionalismo econômico $^{97}$ decorrente da manutenção da economia política como centro organizador dos esforços interdisciplinares, e cuja consequência é um déficit sociológico que limita a capacidade analítica da teoria crítica. Segundo Honneth, apesar de haver intuições importantes nos escritos de Horkheimer do início da década de 1930 (como uma noção ampla de cultura ${ }^{98}$ ), já nessa época é possível distinguir uma tensão entre tais intuições e uma filosofia pessimista da história, que seria mais tarde radicalizada e passaria a dominar sua produção teórica a partir dos anos 1940 .

Há ainda uma última crítica importante direcionada a Horkheimer por mais de um autor e que vai, de certa forma, na direção oposta às críticas anteriores. ${ }^{99}$ Em lugar de objetar no programa horkheimeriano um excesso metafísico decorrente da capacidade organizadora da categoria da totalidade, alguns comentadores censuram justamente o que consideram uma articulação não suficientemente orgânica entre os saberes específicos mobilizados pelo materialismo interdisciplinar. De acordo com esse ponto de vista, não basta tentar unir conhecimentos especializados que, de resto, são conduzidos de modo tradicional

97 Cf. também VOIROL, "Matérialisme interdisciplinaire et critique de la culture", p. 48; KAVOULAKOS, K. "From Habermas to Horkheimer's Early Work: Directions for a Materialist Reconstruction of Communicative Critical Theory", p. 50-51.

98 HONNETH, A. Kritik der Macht; cf., também, a discussão detalhada sobre o conceito materialista de cultura de Horkheimer em VOIROL, "Matérialisme interdisciplinaire".

99 Cf. BONß, W. “The Program of Interdisciplinary Research”; W. KAVOULAKOS, op. cit. 
- é preciso, também, realizar uma crítica epistemológica desses conhecimentos para determinar sua estruturação interna na concepção do todo social:

Such an undertaking, however, seems to ignore the fact that the findings of these specialized studies will already be pre-determined to a certain degree by a specific conceptual framework. So it is not sufficient to synthesize them retrospectively from a holistic perspective; what is needed is that they previously undergo epistemological critique. [...] The dialectic between representation and research ends up resembling a great intellectual effort to coordinate the unrelated findings of specialized studies, under the guidance of theoretically founded concepts. ${ }^{100}$

Se, por conta dessas importantes ressalvas, a teoria crítica dos anos 1930 tal como formulada por Horkheimer já foi considerada ultrapassada, sua capacidade de sobrevivência tem se mostrado surpreendente. Especialmente a partir da década de 1990, observa-se uma tendência crescente entre os autores contemporâneos a se filiar ao menos às intenções desse paradigma de teoria social. ${ }^{101} \mathrm{O}$ que chama a atenção dos teóricos

100 KAVOULAKOS, op. cit., p. 51. É importante notar, quanto a esta última crítica, que Horkheimer estava consciente do problema, apesar de não ter conseguido resolvê-lo na prática (cf. HORKHEIMER, M. "The Present Situation of Social Philosophy", p. 9.).

101 VOIROL, "Matérialisme interdisciplinaire". A renovação do interesse pela teoria crítica de Horkheimer é atestada pela publicação, em poucos anos, de uma coletânea de escritos da década de 1930 (Between Philosophy and Social Science, de 1993) e de dois volumes de comentários (On Max Horkheimer: New Perspectives, também de 1993, e Max Horkheimer heute: Werk und Wirkung, de 1986). 
críticos da atualidade é justamente o caráter ambicioso e refinado do programa interdisciplinar de Horkheimer. ${ }^{102}$ Afinal, a sua adoção da perspectiva da totalidade para conectar as disciplinas individuais não implica uma concepção especulativa do todo social, mas sim o emprego de uma determinada metodologia referente à investigação dos processos sociais. ${ }^{103}$ Esse modo de proceder foi descrita por Horkheimer da seguinte maneira:

chaotic specialization will not be overcome by way of bad syntheses of specialized research results, just as unbiased empirical research will not come about by attempting to reduce its theoretical element to nothing. Rather, this situation can be overcome to the extent that philosophy - as a theoretical undertaking oriented to the general, the "essential" - is capable of giving particular studies animating impulses, and at the same time remains open enough to let itself be influenced and changed by these concrete studies. ${ }^{104}$

Do mesmo modo, Habermas, por exemplo, apesar das duras crítica apresentadas na Teoria da ação comunicativa e no Discurso filosófico da modernidade, destaca que - em que pese o "fantasma" de uma filosofia da história como fio condutor do projeto interdisciplinar - Horkheimer procurou, com o trabalho coletivo no Instituto, dar uma resposta original ao "fim da metafísica". Essa resposta consistiu em tentar salvar o pensamento filosófico mediante sua interação com as ciências sociais: "As

102 VOIROL, "Matérialisme interdisciplinaire"; KAVOULAKOS, op. cit., p. 51. 103 KAVOULAKOS, op. cit., p. 48-49.

104 HORKHEIMER, M. “The Present Situation of Social Philosophy" p. 9. 
long as philosophy cannot be actualized, it must be transferred to another medium in order not to degenerate into ideology - and for Horkheimer this medium should be the social sciences gathered, fused, and renewed in the reflector of critical theory of society". ${ }^{105}$

Desse modo, por conta de sua relação com as teorias sociais, o materialismo interdisciplinar de Horkheimer carrega sempre uma conotação de crítica da filosofia, orientada por um pensamento pós-metafísico - o que, ainda de acordo com Habermas, não foi levando às últimas consequências pelos filósofos e tampouco pelos cientistas sociais. ${ }^{106}$

Independentemente dos obstáculos - tanto teóricos quanto extra-teóricos ${ }^{107}$ - encontrados por Horkheimer e o grupo de

105 HABERMAS, J. "Remarks on the Development of Horkheimer's Work", p. 50. O distanciamento de Habermas com relação a Adorno e sua aproximação de Horkheimer é observável também na parte final de ambos os volumes da Teoria da ação comunicativa. Para Bonß, no entanto, as tentativas de reativar o projeto interdisciplinar, inclusive a de Habermas, invocam Horkheimer mais retórica que substantivamente (BONß, "The Program of Interdisciplinary Research").

106 HABERMAS, J. "Remarks on the Development of Horkheimer's Work". Habermas afirma ainda que, como Marx, Horkheimer acreditava que a filosofia apenas poderia salvar seu conteúdo de verdade ao tornar-se prática. Mas, como as esperanças de uma transformação iminente estavam bloqueadas, o passo intermediário de reconstruir e desenvolver uma teoria científica imune à mistificação idealista adquiriu importância própria (ibid.).

107 VOIROL (“Teoria crítica e pesquisa social”, p. 97-98) destaca que a dificuldade de unir filosofia normativa e ciências sociais empíricas não tem origem apenas em questões puramente internas à teoria, mas é fruto, também, de condições institucionais (como restrições formais e financeiras à colaboração interdisciplinar), assim como da situação particular em que se encontram tanto a filosofia normativa (que, a partir da mudança de paradigma representada pela publicação de Uma teoria da justiça, de John Rawls, dedicou-se exclusivamente à elaboração de princípios normativos, sem recurso aos resultados concretos das investigações sociológicas e antropológicas) quanto as ciências sociais empíricas (que, ultraespecializadas, rejeitam temas normativos e abordagens filosóficas). 
pesquisadores ligados ao Instituto de Pesquisa Social para a plena realização concreta do projeto materialista interdisciplinar, a proposta de uma articulação mais profunda entre filosofia social e ciências empíricas aparece como amplamente atual. Num momento em que o desacoplamento entre as dimensões descritivas e normativas da teoria parece atingir o seu ápice, ${ }^{108}$ uma atualização do projeto horkheimeriano é mais do que necessária para que se alcance uma "análise do capitalismo moderno capaz de considerar a sociedade em suas diferentes esferas de atividade". ${ }^{109}$

A colaboração entreteoria crítica eteoria tradicional em Habermas ${ }^{110}$

Uma atualização do projeto teórico horkheimeriano não pode, contudo, ignorar os desenvolvimentos posteriores da teoria crítica. ${ }^{111}$ A obra de Habermas, por exemplo, constitui

108 Entre os autores que criticam esse desacoplamento destaca-se Axel Honneth, que abre seu mais recente livro justamente com esse diagnóstico e que procura, ao longo de mais de seiscentas páginas, apresentar uma alternativa para esse preocupante quadro (HONNETH, A. Das Recht der Freiheit).

109 VOIROL, "Matérialisme interdisciplinaire", p. 47.

110 Os apontamentos a seguir sobre o modelo crítico de Habermas apoiam-se em uma pormenorizada análise levada a cabo em outro lugar, a qual não é possível reproduzir aqui em detalhes. O que se segue, portanto, são apenas os traços centrais de uma possível atualização do programa inicial de Horkheimer a partir de uma leitura crítica da teoria habermasiana.

111 A ausência de referências a Adorno na análise que segue certamente se fará sentir. Contudo, em que pese sua inegável posição de destaque entre os representantes da teoria crítica, não é possível, aqui, um exame pormenorizado de sua obra. Na realidade, fez-se necessário renunciar a esse exame justamente por ser a teoria de Adorno reconhecidamente um modelo crítico de alta densidade e complexidade, de modo que raramente se alcança um consenso entre os especialistas, seja sobre o conjunto da produção teórica de Adorno, seja acerca de aspectos mais pontuais da obra adorniana. Isso não é menos verdade no tocante 
um passo por assim dizer incontornável no trajeto da teoria crítica: e isso não se deve apenas à introdução da dimensão intersubjetiva e comunicativa no quadro teórico crítico, algo que Habermas persegue em toda a sua obra e que representa um importante desdobramento a ser mantido. ${ }^{112}$ A importância decisiva a teoria habermasiana se fundamenta também no fato de que a ênfase no aspecto comunicativo inaugurou um diálogo e uma incorporação produtiva de outras importantes correntes teóricas, como a fenomenologia, a hermenêutica, as

à relação com as ciências sociais e as pesquisas empíricas. Enquanto, de um lado, pode-se demonstrar o envolvimento de Adorno na formulação e aplicação de investigações de cunho sociológico, é possível também, de outro, questionar o alcance que tais investigações tiveram nos escritos filosóficos adornianos. A ênfase no engajamento de Adorno na pesquisa social aparece, por exemplo, nos seguintes trabalhos: KÖNIG, R. Soziologie in Deutschland: Begründer, Verfechter, Verächter; OLICK, J. K.; PERRIN, A. J. "Translator's Introduction: Before the Public Sphere"; e ALBRECHT, C.; BEHRMANN, G. C.; BOCK, M.; HOMANN, H.; TENBRUCK, F. H. Die intellektuelle Gründung der Bundesrepublik. Como representante da segunda interpretação, por seu turno, Olivier Voirol aponta que a filosofia adorniana manteve-se refratária inclusive relativamente às pesquisas empíricas conduzidas no âmbito do Instituto de Pesquisa Social: "se Adorno realizou amplamente seu trabalho de sociólogo consagrando uma parte importante de sua atividade intelectual ao acompanhamento de pesquisas empíricas no Institut für Sozialforschung ao longo dos anos 1960, seus trabalhos propriamente filosóficos foram desenvolvidos em paralelo à pesquisa social, sem integrar os resultados desta última" (VOIROL, "Axel Honneth et la sociologie. Reconnaissance et théorie critique à l'épreuve de la recherche sociale", p. 248, trad. M. T.). Na impossibilidade de oferecernos, limites deste texto, uma avaliação satisfatória sobre a acuidade de cada um desses polos interpretativos, faz-se necessário deixar a resolução dessa questão para um espaço mais apropriado.

112 Essa é a opinião mesmo daqueles autores que criticam o dualismo excessivo do paradigma habermasiano: cf. HONNETH, A. Kritik der Macht; FRASER, N. "What's Critical About Critical Theory? The Case of Habermas and Gender"; JOAS, H. "The Unhappy Marriage of Hermeneutics and Functionalism"; MCCARTHY, T. "Complexity and Democracy, or the Seducements of Systems Theory". 
teorias linguísticas e a teoria dos sistemas. ${ }^{113}$

Pode-se argumentar que também na trajetória habermasiana há um deslocamento do modelo de teoria crítica a partir da interação com as ciências sociais de um modo geral. Assim, por exemplo, a "reconstrução do materialismo histórico", 114 bem como a crítica ao paradigma teórico no qual se movem Lukács e Horkheimer, ${ }^{115}$ conta com o auxílio daqueles estudos que indicam o esgotamento (teórico e prático) do paradigma do trabalho. ${ }^{116}$ Habermas está atento, portanto, às transformações sociais e históricas do período: "The communicative turn, then, allowed the (of course debatable) detection of a field of practical reason, which one could at least hope would be able to transcend the closed circle of instrumental rationality and domination. Last but not least, this field could be connected with the dynamic of the "new social movements", which became the vehicle of social protest and the claims for democratization after 1968". ${ }^{117}$

Mas a cooperação com diferentes áreas das ciências sociais não se limita, no caso de Habermas, ao estabelecimento de um diagnóstico do tempo (por mais abrangentes que possam ser as

113 Konstantino Kavoulakos chega a afirmar que a teoria de Habermas "rejuvenated critical thought, restored its scientific credibility and provided it with new possibilities to contribute to the process of social emancipation" (KAVOULAKOS, op. cit., p. 53). 114 HABERMAS, J. Para a reconstrução do materialismo histórico.

115 Cf. HABERMAS, J. Teoría de la acción comunicativa.

116 Cf. o diagnóstico do tempo presente em HABERMAS, J. "A nova intransparência: A crise do Estado de bem-estar social e o esgotamento das energias utópicas". Nesse texto, Habermas apoia-se sobretudo nos estudos de Claus Offe e André Gorz (cf. OFFE, C. Arbeitsgesellschaft. Strukturprobleme und Zukunftsperspektiven; GORZ, A. Wege ins Paradies. Thesen zur Krise, Automation und Zukunft der Arbeit).

117 KAVOULAKOS, op. cit., p. 54. 
consequências do diagnóstico para a própria teoria). Isso porque o modelo crítico posto no lugar dos anteriores igualmente apoiase de forma ampla e constitutiva em uma combinação do âmbito crítico da filosofia normativa com o domínio descritivo das teorias sociais tradicionais, ou, em outras palavras, em uma combinação da perspectiva do participante com a do observador. ${ }^{118} \mathrm{O}$ novo modo de relação com as teorias sociais introduzido por Habermas se dá no contexto do estabelecimento de um "paradigma reconstrutivo" para a teoria crítica.

Não é possível, contudo, desenvolver a ideia de "reconstrução" neste espaço. ${ }^{119} \mathrm{O}$ que é importante reter aqui é que, para Habermas, a colaboração entre teoria crítica e as teorias sociais tradicionais se dá em termos de uma complementaridade entre perspectivas parciais (cada uma com o seu "direito relativo" 120 ), e não de uma superação da teoria tradicional como um momento que é visto como necessário a partir da perspectiva que informa a teoria crítica, isto é, a perspectiva da totalidade. Cabe então a pergunta: quais são as consequências dessa transformação metodológica para a interação entre teoria (normativa) e pesquisa

118 Para uma outra forma de ver os distintos modos de relação com as ciências sociais na obra de Habermas, cf. HABER, S. Habermas et la sociologie.

119 Sobre a noção de "reconstrução" em Habermas, cf. PEDERSEN, J. "Habermas' Method: Rational Reconstruction"; REPA, L. A transformação da filosofia em Jürgen Habermas; BAYNES, K. "Rational reconstruction and social criticism: Habermas's model of interpretive social science"; CELIKATES, Kritik als sozialer Praxis; PICHÉ, C. "Entre la philosophie et la science: le reconstructionnisme herméneutique de Jürgen Habermas"; além do recente volume dedicado especificamente ao tema: NOBRE, M.; REPA, L. (orgs.). Habermas e a reconstrução.

120 Cf. HABERMAS, J. Teoría de la acción comunicativa. Cf. sobre isso NOBRE, M. "Teoria crítica hoje". 
(empírica) na teoria crítica atual? Para Voirol, essa interação passou por um processo de complexificação: "a reconstrução também transformou as articulações entre filosofia e ciência, entre teoria e pesquisa, entre fundação normativa e investigação científica, quando comparadas com o modelo dialético do primeiro Horkheimer. Meu ponto é que a relação entre teoria e pesquisa na Teoria Crítica se tornou mais complicada desde a "virada reconstrutiva". ${ }^{121}$

Essa relação se tornou mais complicada precisamente por conta da ausência da categoria de totalidade, o que coloca em risco a articulação dialética entre teoria (apresentação, Darstellung) e pesquisa (Forschung). Sem uma categoria unificadora, a teoria habermasiana acabou porhipostasiarcisões nãomediadas em vários domínios. Enquanto nos modelos lukácsiano e horkheimeriano a interconexão da perspectiva crítica com os saberes especializados sem intenção normativa se dá (ou ao menos pretende se dar) de forma interna, orgânica, e com efeitos recíprocos, a interpretação habermasiana da parcialidade das teorias tradicionais acaba por conferir a elas um "direito relativo" bastante amplo - pelo menos nos seus domínios específicos -, deixando-as em grande medida, portanto, inalteradas em seu fundamento.

Desse modo, se há por parte do teórico crítico um acréscimo da perspectiva do participante à do observador, a conexão assim estabelecida aparece como exterior, mediada de forma insuficiente - como se, na ausência da categoria da totalidade, Habermas não houvesse conseguido encontrar uma nova forma de mediação entre os polos do problema e, assim, acabasse por cristalizá-los

121 Idem, p. 95. 
em um dualismo teórico intransponível. ${ }^{122}$ Permanece, assim, a divisão de trabalho entre filósofos normativos e pesquisadores empíricos ${ }^{123}$ de modo que as suas respectivas atividades mantêmse em um relativo isolamento recíproco.

Como consequência, pode-se dizer que - apesar do modelo reconstrutivo de representar uma renovação essencial da teoria crítica no que se refere ao diálogo com as diversas correntes das ciências sociais tradicionais - fracassou a tentativa habermasiana de formular "um conjunto de hipóteses teóricas que orientassem um programa sistemático de investigações empíricas". ${ }^{124}$

Um novo modelo crítico baseado na dialética entre teoria e pesquisa?

A superação desse dualismo enrijecido, contudo, não pode se dar mediante uma reabilitação da categoria da totalidade pelo menos não nas acepções de Lukács ou Horkheimer. Ela precisa ser atualizada, levando em conta não apenas as viradas "comunicativa" e "reconstrutiva" de Habermas, mas também a consolidação de um ambiente filosófico amplamente pós-

122 Cf. KAVOULAKOS, op. cit., p. 62. Voirol defende que o pluralismo teórico e metodológico da teoria habermasiana permite evitar a divisão do trabalho que levou ao desacoplamento entre filosofia moral e ciências empíricas (VOIROL, "Teoria crítica e pesquisa social", p. 93). Ao nosso ver, esse pluralismo, porque interconectado sem as mediações necessárias, não foi suficiente para evitar a lacuna entre normatividade e imanência e outras cisões que marcam o paradigma habermasiano.

123 No modelo crítico habermasiano, "contrariamente ao programa interdisciplinar proposto por Horkheimer, as pessoas que realizam a pesquisa não são as mesmas que estão produzindo a síntese teórica" (ibid., p. 97).

124 Ibid., p. 96. Para Voirol, há na teoria habermasiana um descompasso entre os polos filosófico e empírico, com primazia do primeiro sobre o segundo. 
convencional. ${ }^{125}$ Tal tentativa terá mais sucesso, segundo o ponto de vista defendido aqui, se for realizada em meio à articulação dialética entre teoria e pesquisa. O procedimento desenvolvido por Marx no Capital e apropriado por autores como Lukács e Horkheimer aparece como o que pode "reequilibrar" a articulação entre imanência e transcendência, que se encontra desajustada na teoria habermasiana.

O método dialético em questão implica que o teórico crítico não se debruce imediatamente sobre o material empírico "bruto", mas tome como ponto de partida outras apresentações acerca desse material; tais apresentações devem, então, ser submetidas elas mesmas à averiguação. ${ }^{126}$ Isso não significa, contudo, que a apresentação tenha primazia sobre a pesquisa, pois a pesquisa tem o poder de reconfigurar a apresentação. Horkheimer cita o próprio Marx a esse respeito: "Research "has to appropriate the material in detail, to analyze its different forms of development, to trace out their inner connexion. Only after this work is done,

125 É o que propôs recentemente, por exemplo, K. Kavoulakos: em "From Habermas to Horkheimer's Early Work", são desenvolvidas algumas indicações para uma "reconstrução materialista da teoria crítica comunicativa". Cf. KAVOULAKOS, op. cit., p. 42: "Therefore, what we need today, on a theoretical level, is a determinate negation of the Habermasian justification of the given, capable of retaining what truth there is in communicative theory, but bringing it under a new theoretical synthesis. As a determinate negation, such a critique cannot, of course, consist in a total (abstract) rejection of communicative theory, but rather in its radicalization toward a more historical, materialist and dialectical theory". Como se percebe, não se trata de uma atualização direta do programa de Horkheimer: ela é mediada pelas transformações implementadas por Habermas na teoria crítica.

126 Não é à toa que Lukács afirme que é preciso partir dos "conceitos unilaterais, abstratos e falsos" da "ciência burguesa", ou que Horkheimer tome como ponto de partida uma crítica da crise da filosofia e das ciências. 
can the actual movement be adequately described". ${ }^{127}$

Assim, o primeiro passo consiste em tomar as teorias ("apresentações") disponíveis - as quais, por sua vez, tiveram origem em pesquisas realizadas anteriormente - e submetê-las a uma investigação que não se furta a novas análises sobre o material empírico, com vistas a uma "síntese teórica provisória que deve definir ela mesma o quadro de pesquisas futuras". ${ }^{128}$

A ideia de que essa síntese é sempre provisória é o elementochave que impede que esse procedimento tenha o mesmo fim que a dialética hegeliana (a identidade entre sujeito e objeto e o saber absoluto). A dialética que caracteriza uma teoria crítica da sociedade deve permanecer sempre aberta: ${ }^{129}$ a apresentação deve poder ser continuamente revisada a partir de novas descobertas. Há sempre um "resto", uma "tensão" nesse processo dialético que nos obriga a reconstruir a teoria sempre novamente.

Isso se deve ao fato de a teoria social crítica lidar com um objeto "vivo", ${ }_{130}^{13}$ que se move ininterruptamente mediante a práxis dos atores sociais. Se a realidade está em transformação constante, a teoria deve estar inscrita em uma dinâmica investigativa visando a abarcá-la sem no entanto jamais consegui-lo por completo -

127 MARX apud HORKHEIMER, M. "The Rationalism Debate in Contemporary Philosophy", p. 237.

128 VOIROL, "Matérialisme interdisciplinaire", p. 26. O autor reforça que não se trata, entretanto, de uma "verificação" ou "falsificação" da teoria o sentido positivista, mas sim de ampliar e enriquecer a síntese teórica para lhe tornar adequada ao objeto (ibid.).

129 Voirol (ibid.) lembra que o papel da teoria dialética, segundo Horkheimer, é reconhecer o caráter imperfeito de toda teoria.

130 KAVOULAKOS, op. cit., p. 49. 
afinal, a prática está sempre um passo na frente da teoria. ${ }^{131}$

É o caráter aberto dessa reconstrução dialética que a permite, portanto, fazer jus a ambas as dimensões que caracterizam a teoria crítica: a análise imanente e o ponto de vista da transcendência. ${ }^{132}$ Ela reconstrói a realidade social tendo como critério as suas potencialidades não realizadas, trazendo assim para o centro das atenções a face do real que "resiste", abrindo-se para a possibilidade de "tornar-se" outro na confrontação com o real e o constante questionamento da própria teoria. ${ }^{133}$

Pode-se argumentar que essa relação dialética exige a reabilitação implausível de uma totalidade metafísica? ${ }^{134}$ Nesse ponto, Voirol ${ }^{135}$ parece ter razão ao afirmar que é possível recorrer a um conceito "fraco" de totalidade que permita pensar a existência de mediações entre diferentes domínios da atividade social, sem no entanto estabelecer o primado de uma determinada dimensão social sobre as outras (como era o caso da esfera econômica não só em Marx, mas em Lukács e Horkheimer). A ideia seria reunir fenômenos ou tendências similares em diversos domínios da realidade em um projeto coletivo de grande envergadura, que procurasse compreender as mediações existentes entre esses domínios sem se submeter à atual fragmentação do saber.

Uma das formas possíveis de interpretar os trabalhos

131 VOIROL, "Matérialisme interdisciplinaire", p. 26-27.

132 Sobre isso cf. CELIKATES, R. Kritik als soziale Praxis. Gesellschaftliche Selbstverständigung und Kritische Theorie.

133 VOIROL, "Matérialisme interdisciplinaire", p. 26-27.

134 Kavoulakos parece ir nessa direção ao afirmar que "Things might be different if we started out from the good old unity of form and content, knowledge and interest, reason and history, theory and praxis" (KAVOULAKOS, op. cit., p. 56).

135 VOIROL, “Teoria crítica e pesquisa social:”, p. 96. 
recentes de Axel Honneth vai exatamente nessa direção. Sua noção de "reconstrução normativa" 136 é um plaidoyer em favor justamente de uma articulação orgânica entre filosofia normativa e teoria social, entre imanência e transcendência. Além disso, a proposta honnethiana de um "programa abrangente de pesquisa" centrado na noção de "paradoxos do capitalismo", estabelecido em 2001 para o Instituto de Pesquisa Social quando Honneth tornou-se seu diretor, ${ }^{137}$ mostra que a conexão entre filosofia moral e ciências sociais ainda goza de grande importância para a teoria crítica.

De fato, o ambiente do Instituto de Pesquisa Social foi capaz, durante certo tempo no início do século passado, de "garantir as condições técnicas de um processo de construção teórica guiado pela filosofia social mas submetido às pesquisa social". ${ }^{138}$ Atualmente, em que pese a fecundidade do projeto honnethiano e da concepção de uma "reconstrução normativa", não parecem estar dadas em Frankfurt as condições práticas e teóricas para a realização dessa concepção exigente de reconstrução dialética: o programa acerca dos "paradoxos do capitalismo" ainda não trouxe inputs substanciais para a compreensão e a crítica das patologias sociais. Isso se reflete na dificuldade observada atualmente na teoria crítica em formular diagnósticos significativos do tempo presente.

Desse modo, o estímulo e a consolidação de novos ambientes

136 Explorada em textos como "Gerechtigkeitstheorie als Gesellschaftsanalyse" e "Rekonstruktive Gesellschaftskritik unter genealogischem Vorbehalt". Cf. ainda, para uma análise mais concreta, HONNETH, A. "Philosophie als Sozialforschung: Die Gerechtigkeitstheorie von David Miller".

137 Cf. HONNETH, A.; HARTMANN, M. "Paradoxien der kapitalistischen Modernisierung. Ein Untersuchungsprogramm".

138 VOIROL, "Matérialisme interdisciplinaire", p. 30. 
de cooperação interdisciplinar, capazes de levar adiante projetos ambiciosos de teoria e pesquisa social, aparece como um dos desafios centrais para a teoria crítica, entendida aqui como um esforço coletivo de articulação entre imanência e transcendência - ou, nos precisos termos de Robin Celikates: "A teoria pode ter esperanças de completar essa tarefa apenas se a filosofia, a teoria social e as ciências sociais empíricas se voltarem, novamente e de maneira revigorada, ao projeto - realizável apenas em conjunto - de fazer valer a força factual do normativo contra a força normativa do factual. ${ }^{139}$

139 CELIKATES, R. Kritik als soziale Praxis, p. 251 (tradução M. T.). 


\section{Referências bibliográficas}

ABROMEIT, John, 2011. Max Horkheimer and the Foundations of the Frankfurt School. Cambridge: Cambridge University Press.

-, "Max Horkheimer et le concept matérialiste de la culture", in: NOPPEN, Pierre-François; RAULET, Gérard; MACDONALD, Iain (orgs.). Les Normes et le possible. Héritage et perspectives de l'École de Francfort. Paris: Éditions de la Maison de sciences de l'homme, p. 53-70.

ADORNO, Theodor W.; FRENKEL-BRUNSWIK, Elsa; LEVINSON, Daniel J.; SANFORD, Nevitt, 1969 [1950]. The authoritarian personality. New York: WW Norton.

ADORNO, Theodor W.; HORKHEIMER, Max, 1985 [1944]. Dialética do Esclarecimento. Fragmentos filosóficos. Trad. G. A. de Almeida. Rio de Janeiro: Jorge Zahar Ed.

ALBRECHT, Clemens; BEHRMANN, Günter C.; BOCK, Michael; HOMANN, Harald; TENBRUCK, Friedrich H., 1999. Die intellektuelle Gründung der Bundesrepublik. Eine Wirkungsgeschichte der Frankfurter Schule. Frankfurt am Main; New York: Campus.

ANTUNES, Deborah Christina, 2012. Por um conhecimento sincero no mundo falso. Teoria Crítica, pesquisa social empírica e The Authoritarian Personality. Tese (Doutorado em Filosofia). São Carlos: UFSCar.

ARATO, Andrew, 1972. "Georg Lukács: The Search for a Revolutionary Subject" in: HOWARD, Dick; KLARE, Karl (orgs.). The Unknown Dimension: European Marxism since Lenin. New York: Basic Books, p. 81-106. 
—, “Lukács' Theory of Reification”, Telos, 11, 1972, p. 25-66.

ARATO, Andrew; BREINES, Paul, 1986. El joven Lukács y los orígenes de lo marxismo occidental. México D. F.: Fondo de Cultura Económica.

BAYNES, Kenneth, "Rational reconstruction and social criticism: Habermas's model of interpretive social science", The Philosophical Forum, 1989, 21, p. 122-45.

BENHABIB, Seyla; BONß, Wolfgang; MCCOLE, John, 1993. "Max Horkheimer: Between Philosophy and Social Science” in: - (orgs.). On Max Horkheimer. New Perspectives. Cambridge, Massachusetts; London: The MIT Press, p. 1-22.

BONß, Wolfgang, 1980. "Kritische Theorie und empirische Sozialforschung: Anmerkungen zu einem Fallbeispiel”, in: FROMM, Erich, [1929]. Arbeiter und Angestellte am Vorabend des Dritten Reiches. Eine sozialpsychologische Untersuchung. Trad. Cornelia Rülke, Rosemarie Thrul e Wolfgang Bonß; organização Wolfgang Bonß. Munique: Dtv, p. 7-46.

—, 1993. "The Program of Interdisciplinary Research and the Beginnings of Critical Theory", in: BENHABIB, Seyla; BONß, Wolfgang; MCCOLE, John (orgs.). On Max Horkheimer. New Perspectives. Cambridge, Massachusetts; London: The MIT Press, p. 99-125.

BONß, Wolfgang; SCHINDLER, Norbert, 1982. "Kritische Theorie als interdisziplinärer Materialismus", in: HONNETH, A.; BONß, W. (orgs.), Sozialforschung als Kritik. Frankfurt am Main: Suhrkamp, p. 31-66. 
CELIKATES, Robin, 2009. Kritik als soziale Praxis. Gesellschaftliche Selbstverständigung und Kritische Theorie. Frankfurt am Main/New York: Campus.

CONGDON, Lee, 1983. The Young Lukács. Chapel Hill: The University of North Carolina Press.

DUBIEL, Helmut, 1985. Theory and Politics. Studies in the Development of Critical Theory. Trad. Benjamin Gregg. Cambridge, Massachusetts; London: The MIT Press.

FEENBERG, Andrew, 1981. Lukács, Marx, and the Sources of Critical Theory. New York/Oxford: Oxford University Press.

FRASER, Nancy, 1985. "What's Critical About Critical Theory? The Case of Habermas and Gender," New German Critique, 35, p. 97-131.

FREITAG, Barbara, 1986. A teoria crítica: ontem e hoje. São Paulo: Brasiliense.

FRISBY, David, 1978. "Introduction to translation" in: SIMMEL, Georg, [1907]. The Philosophy of Money. Trad. Tom Bottomore, David Frisby. London; Henley; Boston: Routledge \& Kegan Paul.

FROMM, Erich, 1984 [1929]. The Working Class in Weimar Germany. A Psychological and Sociological Study. Trad. Barbara Weinberger. Warwickshire: Berg Publishers.

GORZ, André, 1983. Wege ins Paradies. Thesen zur Krise, Automation und Zukunft der Arbeit. Berlin: Rotbuch. 
HABER, Stéphane, 1998. Habermas et la sociologie. Paris: PUF.

HABERMAS, Jürgen, 1983 [1976]. Para a reconstrução do materialismo histórico. Trad. Carlos Nelson Coutinho. São Paulo: Brasiliense.

—, 2003 [1981]. Teoría de la acción comunicativa, vol. 1 e 2. Trad. Manuel Jiménez Redondo. Madrid: Taurus.

—, 1987 [1985]. "A nova intransparência: A crise do Estado de bemestar social e o esgotamento das energias utópicas", Novos Estudos CEBRAP, 18, p. 103-114. Trad. Carlos Alberto Marques Novaes.

—, 2000 [1985]. O discurso filosófico da modernidade. Doze Lições. Trad. Luiz Sergio Repa; Rodnei Nascimento. São Paulo: Martins Fontes.

—, 1993. "Remarks on the Development of Horkheimer's Work", in: BENHABIB, Seyla; BONß, Wolfgang; MCCOLE, John (orgs.). On Max Horkheimer. New Perspectives. Cambridge, Massachusetts; London: The MIT Press, p. 49-65.

HELD, David, 2004 [1980]. Introduction to Critical Theory. From Horkheimer to Habermas. Cambridge, UK: Polity Press.

HONNETH, Axel, 1989 [1986]. Kritik der Macht. Reflexionsstufen einer kritischen Gesellschaftstheorie. Frankfurt am Main: Suhrkamp.

—, 2007 [2000]. "Rekonstruktive Gesellschaftskritik unter genealogischem Vorbehalt: Zur Idee de 'Kritik' in der Frankfurter Schule" in: Pathologien der Vernunft. Geschichte und Gegenwart der Kritischen Theorie. Frankfurt am Main: Suhrkamp, p. 57-69. 
—, 2005. Verdinglichung. Eine anerkennungstheoretische Studie. Frankfurt am Main: Suhrkamp.

—, 2008 [2007]. "Gerechtigkeitstheorie als Gesellschaftsanalyse", in: MENKE, Christoph; REBENTISCH, Juliane (orgs.). Axel Honneth. Gerechtigkeit und Gesellschaft, p. 11-29.

-, 2008. "Vorwort. Philosophie als Sozialforschung: Die Gerechtigkeitstheorie von David Miller" in: MILLER, David. Grundsätze sozialer Gerechtigkeit. Trad. Ulrike Berger. Frankfurt am Main; New York: Campus, p. 7-25.

-, 2011. Das Recht der Freiheit. Grundriß einer demokratischen Sittlichkeit. Berlin: Suhrkamp.

HONNETH, Axel; HARTMANN, Martin, 2010 [2004]. "Paradoxien der kapitalistischen Modernisierung. Ein Untersuchungsprogramm", in: Das ich im Wir. Studien zur Anerkennungstheorie. Berlin: Suhrkamp, p. 222-248.

HORKHEIMER, Max, 1988 [1930]. "Ein neuer Ideologiebegriff?", in: Philosophische Frühschriften 1922-1932. Frankfurt am Main: S. Fischer, p. 271-294.

—, 1993 [1930]. "On the Problem of Truth". Between Philosophy and Social Science. Selected Early Writings of Max Horkheimer. Trad. G. Frederick Hunter. Cambridge, Massachusetts: The MIT Press, p. 177-215.

_, 1993 [1931]. "The Present Situation of Social Philosophy and the Tasks of an Institute for Social Research", in: Between Philosophy and Social Science. Selected Early Writings of Max Horkheimer. Trad. John 
Torpey. Cambridge, Massachusetts: The MIT Press, p. 1-14.

—, 1993 [1932]. "History and Psychology", in: Between Philosophy and Social Science. Selected Early Writings of Max Horkheimer. Trad. John Torpey. Cambridge, Massachusetts: The MIT Press, p. 111-128.

—, 1993 [1933]. "Materialism and Morality", in: Between Philosophy and Social Science. Selected Early Writings of Max Horkheimer. Trad. G. Frederick Hunter. Cambridge, Massachusetts: The MIT Press, p. 1547.

-, 1993 [1934]. "The Rationalism Debate in Contemporary Philosophy", in: Between Philosophy and Social Science. Selected Early Writings of Max Horkheimer. Trad. John Torpey. Cambridge, Massachusetts: The MIT Press, p. 217-264.

—, 1983 [1936]. "Parte geral”, in: Autoridade e família. Trad. Manuela R. Sanches, Teresa R. Cadete. Lisboa: Apáginastantas.

—, 1990 [1936]. “Autoridade e família”, in: Teoria crítica I. São Paulo: Perspectiva/Ed. da USP, p. 175-236.

—, 1975 [1937]. "Teoria tradicional e teoria crítica" in: Benjamin, Horkheimer, Adorno, Habermas (Coleção Os Pensadores). Trad. Edgard Afonso Malagodi, Ronaldo Pereira Cunha. São Paulo: Abril, p. 125-162.

—, 1972 [1937]. "The Latest Attack on Metaphysics", in: Critical Theory. Selected Essays of Max Horkheimer. Trad. Matthew J. O’Connell et alli. New York: Continuum, p. 132-187. 
_, 2004 [1947]. Eclipse of Reason. London; New York: Continuum.

HORKHEIMER, Max; FROMM, Erich; MARCUSE, Herbert et alli, 1987 [1936]. Studien über Autorität und Familie. Forschungsberichte aus dem Institut für Sozialforschung. Lüneburg: Dietrich zu Klampen.

JAEGGI, Rahel; STAHL, Titus, 2011. "Schwerpunkt: Verdinglichung", Deutsche Zeitschrift für Philosophie, 59 (5), p. 697-700.

JAY, Martin, 2008 [1973]. A imaginação dialética. História da Escola de Frankfurt e do Instituto de Pesquisas Sociais, 1923-1950. Trad. Vera Ribeiro. Rio de Janeiro: Contraponto.

—, 1984. "Max Horkheimer and the Retreat from Hegelian Marxism", in: Marxism and Totality. University of California Press, p. 196-219.

JOAS, Hans, 1991. "The Unhappy Marriage of Hermeneutics and Functionalism," in: HONNETH, Axel; JOAS, Hans (orgs.). Communicative Action. Essays on Jürgen Habermas's The Theory of Communicative Action. Trad. J. Gaines e D. L. Jones, p. 97-118.

JÜTTEN, Timo, 2011. "Verdinglichung und Freiheit", Deutsche Zeitschrift für Philosophie, 59 (5), p. 717-730.

KAVOULAKOS, Konstantinos, 2005. "From Habermas to Horkheimer's Early Work: Directions for a Materialist Reconstruction of Communicative Critical Theory", Telos, 130, p. 39-62.

KÖNIG, René, 1987. Soziologie in Deutschland: Begründer, Verfechter, Verächter. Munique: Hanser. 
LUKÁCS, Georg, 1981 [1909]. Entwicklungsgeschichte des modernen Dramas. Darmstadt: Luchterhand.

—, 2003 [1919]. “O que é marxismo ortodoxo?”, in: História e consciência de classe. Estudos sobre a dialética marxista. Trad. Rodnei Nascimento. São Paulo: Martins Fontes, p. 63-104.

—, 2003 [1920]. "Consciência de classe", in: História e consciência de classe. Estudos sobre a dialética marxista. Trad. Rodnei Nascimento. São Paulo: Martins Fontes, p. 133-191.

—, 2003 [1922]. "Prefácio (1922)", in: História e consciência de classe. Estudos sobre a dialética marxista. Trad. Rodnei Nascimento. São Paulo: Martins Fontes, p. 51-61.

—, 2003 [1922]. "A reificação e a consciência do proletariado", in: História e consciência de classe. Estudos sobre a dialética marxista. Trad. Rodnei Nascimento. São Paulo: Martins Fontes, p. 193-411.

—, 2003 [1967]. "Prefácio (1967)", in: História e consciência de classe. Estudos sobre a dialética marxista. Trad. Rodnei Nascimento. São Paulo: Martins Fontes, p. 1-50.

MARCUSE, Herbert 1968 [1937]. "Philosophy and Critical Theory", in: Negations. Essays in Critical Theory. Trad. Jeremy J. Shapiro. Boston: Beacon Press, p. 134-158.

MARX, Karl, 1988 [1867]. O capital. Crítica da economia política, v. 1. Trad. Regis Barbosa, Flávio René Kothe; revisão Paul Singer. São Paulo: Nova Cultural. 
MCCARTHY, Thomas, 1985. "Complexity and Democracy, or the Seducements of Systems Theory", New German Critique, 35, p. 27-53.

—, 1993. "The idea of a Critical Theory and its Relation to Philosophy", in: BENHABIB, Seyla; BONß, Wolfgang; MCCOLE, John (orgs.). On Max Horkheimer. New Perspectives. Cambridge, Massachusetts; London: The MIT Press, p. 127-151.

MEDEIROS, Jonas Marcondes Sarubi de, 2012. Crítica imanente como práxis: apresentação e investigação no ensaio lukácsiano sobre a reificação. Dissertação (Mestrado em Filosofia). São Paulo: FFLCH/USP.

NOBRE, Marcos, 2001. Lukács e os limites da reificação. Um estudo sobre História e consciência de classe. São Paulo: Ed. 34.

—, 2008. "Teoria crítica hoje" in: PERES, Daniel; MATTOS, Fernando; REPA, Luiz et alli (orgs.). Tensões e Passagens. Filosofia crítica e modernidade. São Paulo: Singular/Esfera Pública, p. 265-283.

—, 2004. A Teoria Crítica. Rio de Janeiro: Jorge Zahar.

NOBRE, Marcos; REPA, Luiz (orgs.), 2012. Habermas e a reconstrução. Sobre a categoria central da teoria crítica habermasiana. Campinas: Papirus.

OFFE, Claus, 1984. Arbeitsgesellschaft. Strukturprobleme und Zukunftsperspektiven. Frankfurt am Main: Campus Verlag.

OLICK, Jeffrey K.; PERRIN, Andrew J., 2011. “Translator's Introduction: Before the Public Sphere", in: ADORNO, T. W.; POLLOCK, Friedrich. Group experiment and other writings: the Frankfurt School on Public Opinion in Postwar Germany. Trad. J. K.. Olick e A. J. Perrin. Cambridge/ 
London: Harvard University Press, p. xv-lxi.

PEDERSEN, Jørgen, 2008. 'Habermas' Method: Rational Reconstruction", Philosophy of Social Sciences, 38 (4), p. 457-485.

PICHÉ, Claude, 1986. "Entre la philosophie et la science: le reconstructionnisme herméneutique de Jürgen Habermas", Dialogue, 25 (01), p. 119-142.

POLLOCK, Friedrich, 1980 [1941]. "State Capitalism”, Zeitschrift für Sozialforschung/Studies in Philosophy and Social Science, 9, p. 200-225.

—, 1980 [1932]. "Die gegenwärtige Lage des Kapitalismus und die Aussichten einer planwirtschaftlichen Neuordnung”, Zeitschrift für Sozialforschung, 1, p. 8-27.

REPA, Luiz Sérgio, 2008. A transformação da filosofia em Jürgen Habermas. Os papéis de reconstrução, interpretação e crítica. São Paulo: Singular/Esfera Pública.

QUADFLIEG, Dirk, 2011. "Zur Dialektik von Verdinglichung und Freiheit. Von Lukács zu Honneth - und zurück zu Hegel”, Deutsche Zeitschrift für Philosophie, 59 (5), p. 701-716.

RUGITSKY, Fernando, 2007. "Da crítica da crise à crise da crítica? Uma leitura da obra de Friedrich Pollock", in: Anais do V Colóquio Internacional Marx e Engels. Campinas, SP.

SCHMIDT, Norbet (org.), 1986. Max Horkheimer heute: Werk und Wirkung. Frankfurt am Main: Fischer-Taschenbuch-Verlag. 
SIMMEL, Georg, 1978 [1907]. The Philosophy of Money. Trad. Tom Bottomore, David Frisby. London/Henley/Boston: Routledge \& Kegan Paul.

—, 2013 [1908-1917]. O conflito da cultura moderna e outros escritos. Trad. L. Gagliardi; organização e revisão Arthur Bueno. São Paulo: Senac.

STAHL, Titus, 2011. "Verdinglichung als Pathologie zweiter Ordnung", Deutsche Zeitschrift für Philosophie, 59 (5), p. 731-746.

TEIXEIRA, Mariana O. N., 2010. Razão e reificação. Um estudo sobre Max Weber em História e consciência de classe, de Georg Lukács. Dissertação (Mestrado em Filosofia). Campinas: IFCH/UNICAMP.

—, 2010. "Considerações biográfico-intelectuais sobre um diálogo vivo. Georg Lukács e Max Weber na Heidelberg do início do século XX”, Revista Idéias, 2 (1), p. 97-119.

VASCONCELLOS, Caio Eduardo Teixeira, 2009. "O Moloch do presente". Adorno e a crítica à sociologia. Dissertação (Mestrado em Sociologia). São Paulo: FFLCH/USP.

VOIROL, Olivier, 2007. "Axel Honneth et la sociologie. Reconnaissance et théorie critique à l'épreuve de la recherche sociale", in: CAILLÉ, Alain (org.). La quête de reconnaissance. Nouveau phénomène social total. Paris: Découverte, p. 243-268.

—, 2012. "Teoria crítica e pesquisa social: da dialética à reconstrução", Novos Estudos Cebrap, n. 93, p. 81-99. Trad. Bruno Simões.

—, 2012. "Matérialisme interdisciplinaire et critique de la culture", in: NOPPEN, Pierre-François; RAULET, Gérard; MACDONALD, Iain 
(orgs.). Les Normes et le possible. Héritage et perspectives de l'École de Francfort. Paris: Éditions de la Maison de sciences de l'homme, p. 19-51.

WEBER, Max, 1973 [1918]. "Parlamentarismo e governo numa Alemanha reconstruída", in: Max Weber (col. Os Pensadores), vol. XXXVII. Trad. Maurício Tragtenberg. São Paulo: Abril Cultural, p. 7-91.

_, 2004 [1904-1905]. A Ética Protestante e o "Espírito" do Capitalismo. Trad. José Marcos Mariani de Macedo. São Paulo: Companhia das Letras.

—, 1987 [1920]. "La ética económica de las religiones universales", in: Ensayos sobre sociología de la religión, vols. 1 e 2. Trad. Jose Almaraz, Julio Carabaña. Madrid: Taurus.

—, 1999 [1913-14]. Economia e Sociedade. Fundamentos da Sociologia compreensiva, vols. 1 e 2. Trad. Regis Barbosa, Karen Eslabe Barbosa. Brasília; São Paulo: UnB; Imprensa Oficial do Estado de São Paulo.

WIGGERHAUS, Rolf, 2010. Die Frankfurter Schule. Hamburg: Rowohlt 